\title{
SOBRE EL OBISPADO PAMPLONÉS EN ÉPOCA VISIGODA
}

\author{
por \\ Koldo LarRañaga Elorza \\ Universidad del País Vasoo, Gasteiz-Vitoria
}

\begin{abstract}
RESUMEN
El articulo, en respuesta a uno anterior de J. J. Larrea sobre el mismo objeto, trata de mostrar que el comportamiento de la sede pamplonica en materia de asistencia a los sínodos visigóticos dista mucho de que sea normal, o nada tenga que ver con factores extrafios a la generalidad de las diocesis hispanas. En ese sentido, pone de relieve la serie de circunstancias que hacen difícil la suerte del obispado de Pamplona en el período considerado, y que tienen que ver con la situación de inestabilidad e indefinición política que se produce en la zona tras la caída del Imperio de Occidente. La débil implantación del aparato de poder visigodo en el Norte peninsular - frente a las instancias de poder local o regional, que tratan de labrarse su propio espacio de poder-- explicaría en buena medida, para el autor, la corta historia de asistencias del obispo de Pamplona a los sínodos visigoticos.
\end{abstract}

\begin{abstract}
Arstracr
About the bishopric of Pamplona of the Visighotic period

This paper is written in answer to another from J. J. Larrea about the same subject, and its aim is to prove that the behaviour of the bishopric of Pamplona regarding the attendance at the Visigothic councils was very far from normal, and had a lot to do with factors alien to the generality of Spanish dioceses. With this aim, the author emphasizes the succession of facts that made difficult the position of the bishopric of Pamplona at this period, facts that had to do with the situation of instability and political indefinition that came about in the area after the fall of the Romain Empire. According to the auhor, the weak implantation of the Visigothic power in the North of Spain -facing the holders of local or regional power - would explain to a great extent the short story of attendances of the Bishop of Pamplona at the Visigothic councils.
\end{abstract}


El del obispado de Pamplona en época visigótica ha sido tema bastante recurrente en la historiografía relativa al País Vasco desde que lo tratara J. DE MORET $^{1}$, y ha sido abordado por lo general en el marco de las controversias - suscitadas desde muy temprana hora y aún hoy sin extinguir del todo- en punto a la cristianización de los Vascones y su grado de sumisión o independencia respecto de los reyes godos. J. J. LARREA ha vuelto recientemente sobre el mismo2, y lo ha hecho con mesura y dominio de la materia histórica. Pensamos, sin embargo, que su generoso tratamiento de la misma no se libra de algún que otro achaque, y es a señalar éstos y a redefinir, sobre todo, el estado de la cuestión en el tema indicado en el título a lo que se orientan las páginas que siguen.

El autor arranca de la observación de que el tema del absentismo de los obispos pamplonicas en los concilios visigóticos se ha prestado con excesiva frecuencia a interpretaciones menos correctas, que obedecen, según él, a lecturas apresuradas - viciadas a veces por apriorismos-del escasísimo material documental existente. Y hemos de reconocer que no le falta razón, habida cuenta de los enjuiciamientos tan diversos de que ha sido objeto el tema. Notamos, empero, que, a despecho del esfuerzo de rigor y de asepsia hermenéutica, de que hace gala el autor, no han dejado de deslizarse, en el cuerpo de su argumentación, ciertas inexactitudes e incluso avances interpretativos, para los que creemos honestamente no se hallan en las fuentes los apoyos que pretende. Se trataría, pues, por un lado, de apurar y definir, en la medida posible, los datos que aportan las fuentes; $y$, por otro, de hacer ver lo que pudiera haber de apriorismos igualmente, pero apriorismos de signo contrario, en la lectura que de los mismos hace el autor. Estamos plenamente de acuerdo con éste en que ausencia de representantes iruiñeses en los sínodos visigodos no significa en absoluto que no hubiera a la sazón titulares en la sede de Pamplona, y menos aún que ésta no existiese. Pero de ahí a pretender que el comportamiento de la sede pamplonica en materia de asistencia a los sínodos de la etapa visigoda entrara dentro de lo normal", o nada tuviera que ver con "factores extraños a la generalidad de las diócesis, [fueran] éstos de orden militar, político o religioso"4, va un trecho: justo el que no es lícito ignorar, si no se quiere incurrir en lo que condena la regla del silogismo que dice que nunca debe la conclusión ir más allá de lo que permiten las premisas.

1 Investigaciones historicas de las antigïedades del Reyno de Navarra (1665), Pamplona 1766, pp. 159s; Anales del reyno de Navarra, I (1684), Pamplona ${ }^{2} 1776$, pp. 84s, 87, etc.

2 El obispado de Pamplona en época visigoda, en "Hispania Sacra" 48, 1996, 123-147.

3 Escribe, en efecto: "Pamplona suele ir cuando toda su provincia va, y falta cuando su provincia se muestra reticente a las asambleas toledanas" (Ibid., p. 135).

4 o. c., p. 145.

Sobre la Iglesia Medieval Hispania Sacra 49 (1997) 


\section{PUNTUALIZACIONES SOBRE CIFRAS DE ABSENTISMO.}

Antes de entrar en materia de lecturas o de interpretaciones, vamos a permitirnos alguna puntualización sobre el texto a leer. Según reconoce el propio autor, la sede de Pamplona es "la más absentista de la provincia más absentista de Hispania"s. Pero veamos más en detalle y de forma comparativa los términos de tal absentismo.

Pamplona sólo figura en 4 ocasiones en los concilios visigóticos _-en 5, si la presencia del episcopus Johannes entre los firmantes del decreto de Gundemaro de 610 (inserto en la Hispana, como se sabe, tras las actas del XII concilio toledano de $681^{6}$ ) ha de interpretarse como expresión de su asistencia a un sínodo supuestamente celebrado en dicha fecha ${ }^{7}$-. De Jas iglesias más occidentales de la Tarraconense - sin duda, las más absentistas-, Calahorra se documenta asistiendo en 10 ocasiones ${ }^{8}(11$, si se incluye en su haber la presencia de Mumius entre los firmantes del referido decreto de 610), Tarazona en 7 ocasiones $^{9}(8$, caso de tener en cuenta la presencia de Floridius entre los firmantes

\footnotetext{
5 lbid.

6 Cfr. VIVES, J. Concilios visigóticos e hispano-romanos, Edición preparada por —, con la colaboración de T. MARIN MARTfNEZ y G. MARTINEZ DIEZ, Barcelona-Madrid 1963, pp. 403-497

' Es sabido que no faltan autores que discuten la autenticidad del decreto, $y$ dudan de que dicho sinodo de 610 hubiese tenido lugar. De todos modos, y aun admitiendo que hubiera que dar como falso el decreto, estariamos de acuerdo con el autor en que los supuestos urdidores del mismo hubieran utilizado muy verosímilmente, al confeccionar la lista de suscribientes, documentos auténticos de principios del 8. VII, guardados en los archivos de Toledo. Sobre el lema, GONZÁLEZ, A. El decreto de Gundemaro y la historia del siglo VI, en Los visigodos. Historia y civilizacion (Antigliedad y Cristianismo: 3), Murcia 1986, pp. 159-69, en el que se encontrarán ulteriores referencias.

8 V. en todos los casos, para precisiones y justificaciones, el cuadro adjunto.

- El Stephanus Terraconensis que figura entre los suscribientes del III concilio toledano en la edición de Vives debe ser leídoTuriasonensis oTirassonensis, sin género de dudas. Repárese en que no se hace de él metropolitano, ni su nombre figura en el grupo de los títulares de las iglesias cabeza de provincias: Masona, Eufemio, etc. Pero es que, además, la edición crítica de dicho concilio, que ofrece F. RODRíGuEz (valiéndose al caso de los datos que aporta la tradición manuscrita independiente de las actas del mismo, recogida en la colección de Saint-Maur [v. al respecto MARTíNEZ Dírz, G. Dos nuevos firmantes del $I I /$ concillo de Toledo, en "AHDE" 42, 1972, 636-41]), dice claramente Siephanus Tirassonensis (Concilio III de Toledo. XIV Centenario 589-1989,Toledo 1991, p. 34), y entre los firmantes no obispos documenta un Stephanus... presbyter vices agens Artemi metropolitani Terroconensis episcopi (lbid., p. 35). En el sínodo II de Zaragoza de tres affos después, cuyas actas no precisan la sede de los obispos asistentes, el metropolitano tarraconense es Artemius, $y$, no obstante, continúa figurando en el un Stephanus que sucle adscribirse a la iglesia turiasonense (v., por ej., P. ZAmora: s. v. Tarazona, en el Diccionario de Historia Eclesiástica de España, t. IV, Madrid 1975, p. 2526). Así lo hace también LARREA, J. J. quien retrasa, empero, hasta 592 la fecha de asistencia de los prelados turiasonenses a los concilios visigóticos (o. c., p. 127).
} 


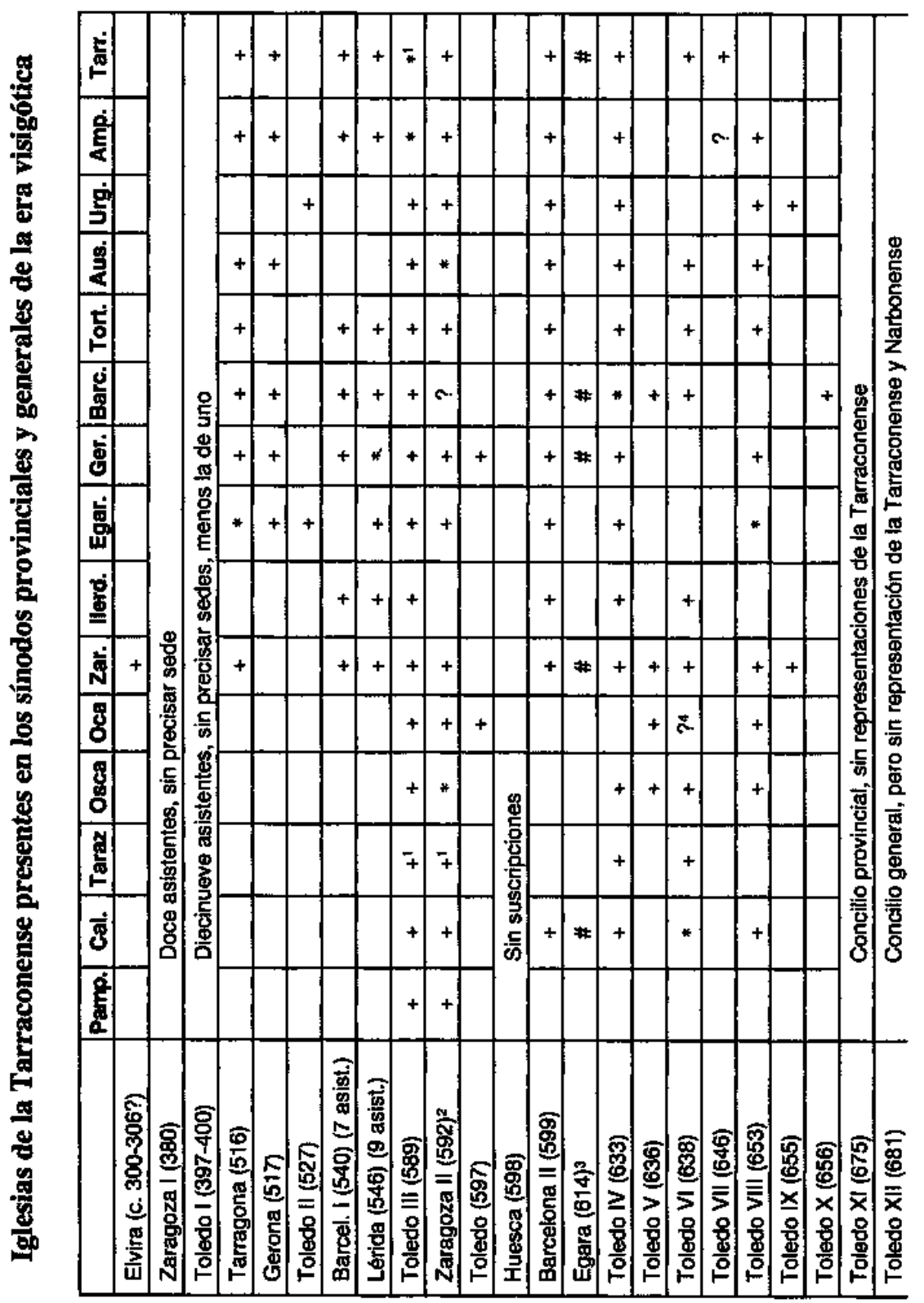

Sobre la lglesia Medieval

Hispania Sacra 49 (1997) 

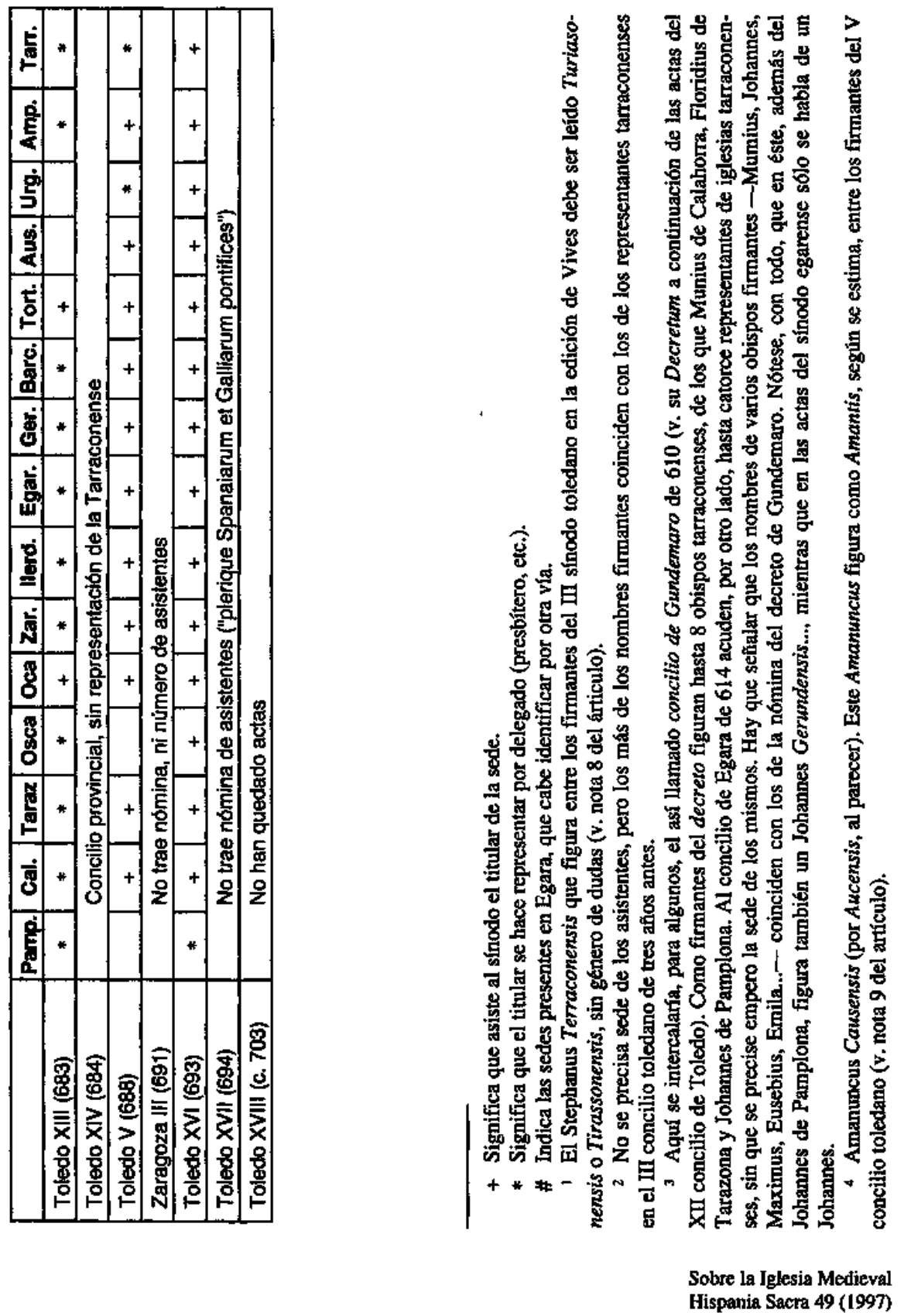
del decreto de 610), Huesca en 8 y en 9 Oca ${ }^{10}$. Zaragoza documenta ya 15 asistencias, ciñéndonos a la etapa propiamente visigoda, y Lérida, la más absentista de las iglesias catalanas, 9 como mínimo. Y es más que verosímil que haya que contabilizar una asistencia más en el caso de ésta, así como en los de Tarazona, Huesca y Oca, habida cuenta de que al sínodo de Egara de 614 asistieron 14 representantes de iglesias de la Tarraconense, algunos de cuyos nombres --Mumius, Johannes, Maximus, Eusebius, Emila- coinciden con los de los firmantes del así llamado decreto de Gundemaro de 610. Es verdad que no cabe identificar con absoluta certeza las 14 sedes representadas en tal sínodo, y es verdad también que en la lista de los obispos que asisten al mismo figura un Johannes que cabe identificar con el homónimo Pampilonensis ecclesiae episcopus, que documenta el así llamado decreto de Gundemaro de cuatro años antes. Pero no es menos cierto que en éste figura también un $J o-$ hannes Gerundensis, y que, tratándose de asistencias a sínodos visigoticos, no es justamente la sede pamplonica la más indicada para competir con otras en el cálculo de probabilidades.

Lo que sea de esto último, opinamos que las cifras avanzadas ofrecen un cierto margen de seguridad para algunas consideraciones. El índice de asistencia sinodal de las iglesias tarraconenses más occidentales --las más absentistas, según queda dicho- es cuando menos el doble que el de la iglesia de Pamplona, salvo en el caso de la de Tarazona, que llegaría, empero, al doble, si se contabiliza en su baber la asistencia al concilio egarense de 614. Ahora bien, estimamos - y entraríamos ya en el orden de las interpretaciones- - que se trata de una diferencia significativa, que hace del pamplonés un caso un tanto atípico, en cuanto a asistencia sinodal, no sólo a nivel de la iglesia hispana, sino incluso de la tarraconense, reconocida como la más absentista de todas. El hecho podrá ser explicado en función de unas razones u otras y valorado de acuerdo con las mismas; pero en cuanto tal no deja de constitujr una singularidad que requiere explicación plausible, máxime si se tiene en cuenta que la de la asistencia a los sínodos es un deber de los representantes de las iglesias, sobre el que insisten una y otra vez los cánones conciliares, conminando con penas muy graves a los negligentes ${ }^{11}$. No cabe despachar como anécdota irrelevante el caso de una sede que, en un lapso de unos doscientos años, documenta sólo cuatro asistencias a las asambleas sinodales, cuando de sus coprovinciales - y para el mismo lapso de tiempo- unas documentan el triple de

10 El Amanuncus Causensis que figura entre los firmantes del VI concilio de Toledo resulta, a no dudar, un error de transcripción por Aucensis, pues no se reconoce una sede episcopal que responda por Causensis. A ese Amantncus se reduciría, por otro lado, el Amantius, ecclesiae Aucensis episcopus, que el codice vigilano de la Hispana pone entre los firmantes del $\mathrm{V}$ concilio toledano de dos años antes.

${ }^{11}$ Cfr. Conc. Nic., c. V; Conc. Chalc., c. XIX; Conc.Tarrac., c. VI; Conc. Brac. II, cc. XVIII y XIX; Conc. Emer., VII, elc.

Sobre fa Iglesia Medieval

Hispania Sacra 49 (1997) 
asistencias, y las que menos, el doble. Y no cabe despacharlo así, porque, aun habida cuenta de que, en la práctica y por lo común, dista mucho de que los concilios, tanto provinciales como generales del reino, se convoquen con la periodicidad preconizada, o que los obispos asistan a los mismos con la asiduidad requerida, la práctica documentada de las iglesias más próximas a Pamplona nos dice que los titulares de ésas se comportan bastante mejor, por lo que hace a asistencia sinodal, que los titulares de la iglesia iruiñesa. ¿Las razones de ello? ¿Cuestión sólo de itineris longitudo y paupertas ecclesiarum, que son, según sabe, los motivos que aducen los padres del III sínodo toledano del 581, para rebajar de dos a uno por año la norma canónica de celebración de los sínodos provinciales ${ }^{12}$ ?

\section{PAMPLONA Y LOS SÍNODOS PROVINCIALES, DE LA PRIMERA MITAD DEL S. VI}

La iglesia iruiñesa no se documenta en los concilios visigodos sino a partir del III de Toledo de 589. Se halla ausente, así, de los provinciales de Tarragona (516), Gerona (517), Barcelona I (540) y Lérida (546). Se trata de ausencias - las relativas a dichos cuatro sínodos provinciales- que J. M. LARREA explica afirmando que "sólo conciernen a la parte oriental de la Tarraconense", e. d., a lo que será Cataluña, más a Zaragoza ${ }^{13}$. Lo cierto es que faltan también a los mismos los representantes de Huesca, Tarazona, Calahorra y Oca, lo que parece conferir cierta plausibilidad a su afirmación. Pero ¿no cabría hurgar más hondo, y preguntarse -a partir de lo que permiten rastrear las fuentes sobre lo que acaece por entonces en esa zona más occidental de la Tarraconense- por las razones que determinan tales ausencias? ¿En qué se basa el autor para decir que dichos concilios sólo conciernen a las iglesias catalanas más a

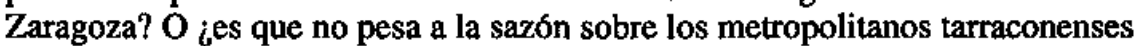
la obligación de convocar periódicamente a sus sufragáneos, o sobre éstos, la de acudir puntualmente, de no mediar razones de peso, a los sínodos a que son convocados? Y puestos a inquirir sobre las razones de tan prolongada ausencia de tantas iglesias, ¿sería mucho prejuzgar una cierta situación de inestabilidad o de indefinición política en la zona, situación de indefinición, propiciada por las difíciles circunstancias por que atraviesa a la sazón el poderío visigodo en la península, y de la que se aprovecha el elemento vascón y cántabro (o los poderes locales que se ocultan bajo tales nombres) para asegurarse su propio espacio de poder en la zona?

\footnotetext{
12 C. XVIII (ed. de J. VIVES, p. 131).

I3 O. c., p. 130.
} 
Es un hecho, por lo pronto, que las fuentes, excepto en una ocasión, no vuelven a referirse al área hasta bastante años después -en concreto, hasta que Leovigildo, decidido a realizar su sueño de unidad peninsular, pasa a atacar a cántabros $(574)^{14}$ y vascones $(581)^{15}$ - La excepción a que se alude tiene que ver con la marcha que los Francos, conducidos por Childeberto y Clotario, protagonizan el 542 sobre el valle del Ebro. Según precisa la así llamada Chronica Caesaraugustana, la expedición -que es invocada por algunos como el origen del supuesto ducado franco de Cantabria, de que habla cierto enigmático pasaje del Pseudo-Fredegario ${ }^{16}$ __ sigue, en efecto, la ruta de Pamplona, para abatirse sobre el valle medio del Ebro ${ }^{17}$. Ahora bien, aun dando por probado que la expedición nada tiene que ver con los orígenes de ese fantasmal ducado de Cantabria, y que el éxito de la misma dista mucho de que sea todo lo rotundo que pretenden las fuentes de adscripción merovingia ${ }^{18}$, ino cabe considerar el hecho de la correría en sí (per quadraginta novem dies omnem fere Tarraconensem provinciam depopulatione triverunt, precisa la Crónica referida) como el síntoma de una situación político-militar cuando menos poco definida y consolidada en la zona? No se olvide que la estructura de poder goda se ve seriamente comprometida en la península tras el desastre de Vouillé, según es lícito conjeturar, y que no ayudarán precisamente a su recuperación y fortalecimiento los años que siguen, marcados por luchas intestinas, reinados cortos, minorías de edad, ambiciones expansionistas de Ostrogodos,

14 JOHANNES BICLARENSIS: Chron. [ad ann. 574?] (ed. de TH. MOMMSEN, p. 213).

is JohanNes BICLARENSIS: Chron., [ad ann. 581?] (ed. de TH. MOMMSEN, p. 216).

is Chronicarum quae dicuntur Fredegarii Scholastici Libri IV cum continuationibus, IV, 33 (ed. de B. KRUSCli en $M G H, S R M$, II, Hannover 1888, p. 133). Sobre el tema, v. K. LARRAÑAGA Elorza; El pasaje del Pseudo-Fredegario sobre el dux Francio de Cantabria y otros indicios de naturaleza textual y onomastica sobre presencia franca tardoantigua al sur de los Pirineos, en "Archivo Español de Arqueología" 66, 1993, 177-206.

17 Ad ann. 542 (ed.de TH. MOMMSEN en MGH, AA., $11^{2}$, Berlin 1894, pp. 222-223, concret. p. 223): Hoc anno Francorum reges $V$ per Pampelonam Hispanias ingressi Caesaraugustam venerwht, qua obsessa per quadraginta novem dies omnem fere Tarraconensem provinciam depopulatione triverunt.

18 Según es sabido, sobre el hecho, además del breve apunte de la Chronica Caesaraugustana, contamos con el relato - algo posterior y más desarrollado- de GREGORIO DE TOURS (Hist., III, 29 [ed. de B. KRUSCH,-W. LEVISON en $M G H, S R M$, t. V1, Hannover 1951, pp. 125s]), que presenta los hechos en una luz favorable a las armas francas $y$, por último, con la versión ofrecida por SAN ISIDORO en su Historia Gothorum (41 [ed. de C. RoDrígueZ ALONSO, León 1975, p. 240]), que habla de un descalabro infligido por el dux godo Teudisclo a los invasores francos. -Es probable por filtimo, que haya que entender referido a este suceso un breve pasaje de JORDANES sobre el rey Theudis (Francorum insidiosam calumniam de Spaniis pepulit - dice en su De origine actibusque Getarum, 58, 302 [ed. de TH. MOMMSEN in $M G H, A A, V 1$, Ber]in 1882, pp. 135s]): testimonio rigurosamente coetáneo que, de referirse - como sospechamos-a la expedición franca de 542, avalaría en su concisión la versión isidoriana de los hechos.

Sobre la Iglesia Medieval Hispania Sacra 49 (1997) 
Francos y Bizantinos y veleidades autonomistas de la poderosa aristocracia hispanorromana. El éxito que Isidoro y Jordanes atribuyen a Theudis en su enfrentamiento al invasor franco puede en tal sentido ser interpretado como un primer paso hacia el enderezamiento de la situación en la zona, paso, empero, que no parece tiene continuación - por razones análogas a las apuntadas- en los dos o tres decenios siguientes, hasta la entrada en escena de Leovigildo. En tal coyuntura, ¿puede extrañar la no presencia de las iglesias occidentales de la Tarraconense en los sínodos de los años entre 515-546? La presencia de Zaragoza en los mismos ¿no marcaría, más bien, el límite hasta donde se hace operativo de momento en el valle del Ebro ${ }^{19}$ un poder visigótico indeciso que, por lo que parece, no acierta a identificarse todavía plenamente con el espacio global peninsular como ámbito de realización ${ }^{20}$ ? Cabe referirse, por otro lado, a lo que indicios coincidentes, tanto de orden textual como arqueológico, vienen sugiriendo sobre lo que a la sazón está sucediendo en el área.

Tenemos, ante todo, ciertos pasajes de VENANCIO FORTUNATO referidos a los vascones ${ }^{21}$, pasajes que, por muy sobrados de retórica y tópicos que se quieran $^{22}$, no significan menos la aparición inaugural, en el escenario histórico,

19 Son múltiples los indicios que apuntan a la importancia que desde hora muy temprana se cobra Zaragoza en el disej̃o estratégico godo de penetración y dominación peninsular (cfr., por ej., Chron. Gallica a. DXI, 651-652; Chron. Caesar., ad a. 506, etc.), por lo que no es de extrafiar que en las horas bajas que siguen al desastre de Vouillé continúe todavía siendo la ciudad del Ebro uno de los puntales de la estructura de poder visigoda en la zona. Son varios los autores que han venido a subrayar la importancia de Zaragoza en el diseño estratégico godo: v., por ej., ORLANDIS, J. Zaragoza visigótica, Zaragoza 1968; LACARRA, J. M. Historia de Zaragoza. I. Edades Anigua y Media, Zaragoza 1976, pp. 96s; GARCía IGLESIAS, L. Zaragoza, ciudad visigoda, Zaragoza 1979; DomíngUEZ MONEDERo, A. J. La "Chronica Caesaraugustana" y la presunta penetración popular visigoda en Hispania, in Los visigodos. Historia y civilización. Actas de la Semana Internacional de Estudios Visigónicos. Madrid - Toledo - Alcalá de Henares, 21-25 octubre de 1985, Murcia 1986, pp. 61-68, part. 64s).

20 Cfr. García de Cortázar, J. A. La época medieval, en M. ARtola (dir.); Historia de España Alfagwara, Madrid 1973, pp. 14 y 30.

${ }_{21}$ Carm., Append. II, 2, vy, 29s y 83s (ed. de FR. LEO, pp. 276s); Carm., IX, I, 73-74 (Ibid., p203). Puede verse también Carm., X, 19: Ad Galactorium comitem, vv. 1-12 (ed. de F. LEO, p. 251).

22 Parece estar hoy de moda entre ciertos autores el rebajar o cuestionar el valor probativo de los textos desde el punto en que se evidencia en ellos cualquier traza de utilización de estereotipos o clichés literarios. Convengamos, sin embargo, en que lo que procede en tales casos es, en principio, no rebajar y menos todavía negar el valor probativo del texto como tal, sino aislar en él el cliché o tópico de que se trata y traducirlo, si posible, a contenidos históricos verificables. Sólo cuando csto no fuera posible sería cuestión de ignorarlo. $Y$ es que no debe olvidarse, tratando de tópicos o lugares comunes, que tópico en cierto sentido lo es todo o casi todo en materia de lenguaje. En su origen el cliché responde a una necesidad expresiva. Trata de fijar o de acotar semánticamente, en función de las necesidades de un grupo, su juicio valorativo de un hecho, de una colectividad. A veces parece responder a meros convencionalismos sin mayor trascendencia, al revelarse exento de acrimonia o de valoraciones negativas. Otras se diría responder a la necesidad de neutralizar, demonizandolo, un 
del vascón díscolo y difícil que durante generaciones habitará el imaginario erudito tardoantiguo y altomedieval, llenando de zozobras y recelos a los rectores de las patrias cristianas ${ }^{23}$. Y al hablar de esta guisa, no nos olvidamos del inquietos Vasconas que AvIENo, a fines del s. IV, interpola, según parece, en su traducción versificada del texto de un viejo periplo fenicio-masaliota ${ }^{24}$; ni de las palabras con que apostrofa PRUDENCIO a la bruta Vasconum gentilitas de antaño ${ }^{25}$; ni de textos como los de Ausonio y PAulino, en que se hace referencia a la barbarie, incivilidad e inhumanidad de los vascones ${ }^{26}$. Sólo queremos significar que la sensación de extrañeza (?) que pasajes como ésos dejan traslucir en sus autores respecto de la penosa situación cultural de los vascones, sólo viene a ser eso, según entendemos: extrañeza ante su penosa situación cultural, sin que ésta en ningún caso rebase la consideración de un problema interior al Estado romano (en el caso de Avieno, si hubiera que ver a éste como autor de la interpolación) y al propio universo doméstico (en el de los autores aquitanos o de Prudencio); al tiempo que en los pasajes referidos de Venancio Fortunato los Vascones (y cabría, sin duda, hacer extensiva esa consideración a los Cántabros) vienen a configurarse como potencial amenaza o instancia exterior, al situárselos a un mismo nivel que otros pueblos indepedientes (Dani, Saxones, Britanni...). Quiero decir que en este caso se trataría de algo más que de un tópico, al constituir tales textos - a datar el primero hacia el 570; hacia el 580, el segundo- la primera constatación documental de que el mundo vascónico empieza a ser percibido y connotado como un entorno hostil para una formación política de rango reconocido.

Lo que, en todo caso, resulta más problemático es atinar con las razones concretas que hacen que, a partir de cierto momento, la intelligentsia franca perciba al vascón como un mundo potencialmente peligroso. ¿Qué hechos de invasión o de pillajes protagoniza aquél hasta ese momento, que justifiquen una tal imagen? Mirando hacia atrás y tratando de hallar algo, cabría traer a colación aquí las revueltas bagaudes de hacia mediados del siglo $\mathrm{V}$, sólo que

ámbito o un hecho que es sentido como nocivo o potencialmente peligroso para la seguridad del propio grupo. Lo que, en cualquier caso, resta por saber es por qué un autor echa mano de un cliché, y no de otro, al etiquetar a una colectividad, describir una situación o referirse a unos hechos. Sobre el ejemplo que aduce el autor en la p. 144, tomándolo de $\mathrm{M}$. Bloch, cabría en cualquier caso argüir que, llegado el caso, Eginhard ccha mano, no precisamente de la pintura que Suetonio hace de Domiciano, sino de la que el mismo autor traza de Augusto. Sobre esto volveremos a insistir más adelante, en el ûltimo epigrafe.

23 V. comentados los pasajes citados en BARBERO, A. - ViGlul, M. Sobre los origenes sociales..., pp. 5 Is y 55s; RouCHE, M. L'Aquitaine des Wisigoths aux Arabes (418-781). Naissance d'une région, Paris 1979, pp. 88s, más las notas 7 y 20 del capitulo correspondiente (pp. 503 y 505).

24 Ora maritima, v. 251.

25 Perist. 1, 94.114.

26 Epist. 29, 50-63; Epist. 31 [Paulini Epist. X], 189-264.

Sobre la Iglesia Medieval

Hispania Sacra 49 (1997) 
interpretándolas $\rightarrow$ a título de hipótesis, cuando menos- como algo más que episodios de lucha de clases ${ }^{27}$. Sobre eso, M. RoucHE señala varios otros hechos que se recogen en las fuentes, y que, según él, pueden ser interpretados como indicios de expansión o de insurgencia vascona. Así, el saqueo de lasVasconias, a que en su camino a Tolosa se entrega Rechiarius el 449 (coincidiendo de lleno - conviene recordarlo- con la crisis bagáudica) ${ }^{28}$, es interpretado por el historiador francés como respuesta a supuestos actos previos de hostilidad de los Vascones ${ }^{29}$. Igualmente, y sobre la base de una referencia harto tardía de IBN KHALDUN ${ }^{30}$, Rouche cree poder afirmar que en un momento de su reinado Eurico se ve en la precisión de repeler a los Vascones $^{31}$. Por otro lado, la circunstancia de que Alarico II se halle en Aire-surl'Adour, cuando en el 506 promulga su célebre Breviarium, es interpretada por él - a título puramente conjetural, desde luego- como indicio de una posible agitación vascona, que habría llevado al rey tolosano a personarse en la pequeña ciudad novempopulan $a^{32}$. En fin, entre los indicios de índole textual, delatores de la existencia de un problema vascón, señala - a título conjetural también esta vez- el canon I del sínodo de Lérida del año 546, según el cual deben ser removidos del ministerio y de la comunión por dos años aquellos clérigos servidores del altar, que, puestos en el trance de un asedio, mancillan sus manos con sangre humana, incluso enemiga ${ }^{33}$, supuesto de asedio o de incursión hostil, que, para M. ROUCHE ${ }^{34}$, que sigue en esto a E. A. THOMPSON ${ }^{35}$, sólo po-

27 V. nuestro punto de vista al respecto en Un tema controvertido: la relacion entre los Vascones y la ast llamada Bagaudia Tarraconense, [comunicación al] II Congreso General de Historia de Navarra, Pamplona-Estella 24-28 septiembre de 1990, in "Príncipe de Viana" 53, Anejo 14, 1992. pp. 229-41.

${ }^{28} \mathrm{Cfr}$. HIDACIO 140.

29 L'Aquitaine..., p. 88.

${ }^{30}$ La historia de los Godos, trad. esp. de O. A. MACHADO in Cuadernos de Historia de España, Buenos Aires, 1-2, 1944, p. 151. Pero ¿no cabría ver en la referencia de Ibn Khaldun a los "Baskanas" sometidos por Warigus (Eurico) un eco de la noticia recogida por la Chronica Gallica a. DXI (651) y transmitida también por ISIDORo (Hist. Goth., 34), que habla de la ocupación visigoda de la Tarraconense per Pampilonem Caesaraugustam et vicinas urbes? De ser eso así, quedaría por elucidar a qué se reducen csos Baskanas que se resisten a Eurico: ¿vascones propiamente dichos, en el sentido que el etnónimo se cobra bajo la pluma de los autores hispanogodos y francos, o, más bien, nobles hispanorromanos afincados en Pompaelo, que, al igual que otros de la Tarraconense, se oponen al bárbaro?

${ }^{31}$ L'Aquitaine..., p. 88 y nota 5 (p. 503).

32 Les relations transpyrénéennes du Ve au VII ${ }^{e}$ siècle, in Les communications dans la Peninsule lbérique au Moyen Age. Actes du Colloque tenu à Pau les 28 et 29 Mars 1980 sous la direction de P. Tucoo-Chala, Paris 1981, pp. 13-20, concret. 5 n. 16.

${ }^{33}$ Ed. de J. VIVES, p. 55.

34 L'Aquitaine..., p. 503 nota 5 . Personalmente, no estaríamos tan seguros de que tal supuesto, a la sazon, sólo pudiera tener sentido referido a los Vascones, porque pocos affos antes (h. el 541) la zona del Ebro medio en tomo a Zaragoza resulta víctima de una formidable invasión franca (v. las referencias que se recogen en las $\mathrm{nn}$. 15 y 16). 
dría ser entendido a la sazón en referencia a los Vascones. Giros hermenéuticos, como se ve, que legitimaría o, al menos, excusaría la necesidad de hallar una explicación plausible a lo que conocemos sobre la historia inmediatamente posterior del área, pero para los que difícilmente pueden hallarse anclajes suficientes en la literalidad de los textos.

Es con posterioridad a los pasajes comentados de Venancio Fortunato, cuando empieza a haber pruebas más concluyentes sobre el antagonismo existente entre los Vascones, por un lado, y Francos y/o Visigodos, por otro, a comenzar por el ataque que Leovigildo conduce h. el 574 contra los Cántabros, y siguiendo por los que Bladastes, en la vertiente Norte, y el mismo Leovigildo, por el Sur, protagonizan contra los Vascones justo en el 581. Pero, en cualquier caso, los textos algo anteriores de Fortunato vienen a revelar, a su manera, que algo ha ido fraguándose en el mundo vascón desde los días un tanto lejanos en que Prudencio o sus coetáneos Ausonio y Paulino hacían retórica en punto a la penosa situación cultural de los Vascones: algo que condiciona, como se ha visto, la nueva forma en que es percibido el vascón por el poeta álico, y que, a falta de mejores términos de referencia, cabe relacionar con el bullir de los particularismos cantonalistas o de otro tipo ${ }^{36}$, que documentan los autores en relación con la primera mitad del s. VI. Y es ese algo, hecho de resistencia antirromana y antigermánica $o$, si se quiere, de particularismo cantonalista ${ }^{37}$, estimamos, el que puede estar también en el origen del absentismo sinodal de las iglesias del área en la etapa comprendida entre el 516 y 589: como lo está de las acciones militares que habrá de protagonizar el aparato de poder visigodo o franco a partir del último cuarto del s. VI.

Por lo que hace a los indicios de orden arqueologico, hay que referirlos a la serie de hallazgos - - a remitir al periodo tardoantiguo--, que se han producido

35 Los Godos en España, Madrid 1971, p. 21.

${ }^{36} \mathrm{Cfr}$. GIBERT, R. El reino visigodo y el particularismo español, in "Estudios visigóticos" (Roma-Madrid) 1, 1956, pp. 15-47; GARCía MORENO, L. A. Problemática de la Iglesia hispana durante la supremacía ostrogoda, in Hispania Christiana. Estudios en honor del Prof. José Orlandis, Pamplona 1988, pp. 147-160; UdNA MARTORELl, F. La Tarraconense y la Narbonense en la época del III Concilio de Toledo, in Concilio III de Toledo..., pp. 641-657.

37 iSe ha reparado suficientemente en el hecho de que el episodio de Silvano de Calahorra, casi un siglo antes, define un escenario de enfrentamiento parecido al que marcan ahora las sedes asistentes de la Tarraconense, por un lado, y las absentistas, por otro? Frente al metropolitano Ascanio y unos obispos del área oriental de la provincia, según parece, que hacen causa común con el de Zaragoza, se sitúa el obispo calagurritano, al que apoyan, si no los titulares de las sedes occidentales (no se olvide que tres de ellas - Huesca, Oca y Pamplona - están por documentarse todavía como tałes sedes episcopales...), los honorati y possessores de Turiaso, Cascantum, Calagurris, Varegia, Tritium, Levia y Virovesca. Referencias básicas sobre el affaire de Silvano de Calagurris, en LARRAÑAGA ELORZA, K. En torno al caso del obispo Silvano de Calagurris. Consideraciones sobre el estado de la Iglesia del Alto y Medio Ebro a fines del Imperio, in "Veleia" 6, 1989, 171-191. 
en el país en los últimos años, hallazgos que han supuesto, por un lado, un incremento más que notable de los datos que poseíamos sobre esa edad, y que pueden, por otro, arrojar luces decisivas para esclarecer el sentido de ciertos hechos y procesos apenas desvelados en las pocas y escuetas referencias contenidas en los textos de época sobre las gentes del área. Estamos refiriéndonos al hallazgo de las necrópolis de Aldaieta (Nanclares de Ganboa, Araba), Buzaga (Elorz, Nafarroa), Fínaga (Basauri, Bizkaia) y Alegría-Dulantzi (Araba). Esas necrópolis delatan episodios de asentamiento estable de comunidades humanas con notable presencia de lo militar ${ }^{38}$, episodios que se protrahen desde mediados del s. VI a todo lo largo del VII e inicios del siguiente, y que, por el carácter de los ajuares que vienen arrojando, remiten a un horizonte de cultura material, no godo o hispano-visigodo, sino de adscripción norpirenaica a todas luces, el que cabe genéricamente calificar como franco y en ciertos casos - el de Buzaga o el de ciertos objetos recuperados en el así denominado cementerio visigodo de Pamplona- de facies aquitana. Conviene, además, señalar que, a la luz de los datos que viene arrojando la prospección de tales necrópolis, se ha podido proceder a una lectura más ajustada de ciertos materiales de problemática y equívoca caracterización, que de años atrás habían arrojado otros yacimientos y hallazgos sueltos (así, los del llamado cementerio "visigodo" de Pamplona, los hallazgos alaveses de Guereñu y tal vez también de Salvatierrabide y Guereña, los de ciertas estelas tabulares del área vizcaína próxima a Fínaga-Basauri) ${ }^{39}$.

Hay, en fin, un hallazgo numismático, que vendría a abonar el supuesto de un valle del Ebro periódicamente conmocionado por las razzias vasconas ${ }^{40}$. Se trata de una moneda acuñada por Leovigildo en Rosas, moneda que lleva la

38 Según señalan los autores, resulta francamente llamativo el porcentaje del armamento presente en los ajuares recuperados.

39 V. al respecto AZKaRATE GARAl-OLAUN, A. Algunas consideraciones sobre la arqueologfa de épaca germánica en Euskal Herria, en "Munibe. Antropología-Arqueología" 42, 1990, 345-55; ID.: El eremitismo de época visigotica. Testimonios arqueologicos, en $I V$ Seminario sobre el monacato (m "Codex Aquilarensis" [Aguilar de Campoo] 5, 1991), pp. 141-179; ID.: Francos, Aquitanos y Vascones. Testimonios arqueológicos al sur de los Pirineos, in "AEA" 66, 1993, 149-176; ID.: Algunas consideraciones sobre el siglo VII en el entorno circumpirenaico accidental, in I Congresso de Arqueologia Peninsular (Porto 1993). Trabalhos de Antropologia e Etnologia, vol. 34, 1994, Actas IV, 307-329; Id.: Wasconia, in Gran Atlas Hist6rico de Euskal Herria, Bilbao: Lur argit., 1995, pp. 49-64; AZKARATE GARAj-OLALN, A. - GARCIA CAMINO, I. Estelas e inscripciones medievales del País Vasco (Siglos VI-XI).J. País Vasco Occidental - Euskal Herriko erdi aroko hilari eta inskripzioak (VI-XI. mendeak). I. Euskal Herriko Mendebaldea, Bilbo 1996, part. pp. 153-60, 166-71, 325s; GarCia CAMtNo, I. y UnZUETA, M. Necropolis de Finaga, Basauri, in Arkeoikuska 94, Vitoria 1995, pp. 339-344.

49 ¿Habria que relacionar estas en algún modo con los grupos humanos que habitan en Buzaga, Aldaieta, Dulantzi, etc.? 
leyenda CUM D I RODA, y que, según sugiere G. C. MnES ${ }^{41}$, cabe datar en el 581 o, cuando menos, entre el 580 y $584^{42}$. Ahora bien, según entiende E. A. THOMPSON (para quien la acción antivascona de Leovigildo del año $581^{43} \mathrm{se}$ halla presumiblemente motivada por un previo poderoso hostigamiento de éstos, en el que bajan de sus montañas mucho más de lo normal...), esa leyenda debe ser leída "cum Deo intravit Rodam"; y, al no constarle por ningún lado al autor que Hermenegildo se haga nunca con una ciudad tan alejada como Rosas, ni que a la sazón la ocupen o amenacen los Francos, concluye que la única explicación plausible para tal inscripción se halla en el hecho de que los Vascones "[...] hubieran conseguido descender por el valle del Ebro hasta alcanzar la costa mediterránea y finalmente ocupar Rosas"

A los indicios de naturaleza textual y arqueológica se suma todavía el que supone la paulatina desaparición -en las crónicas y práctica erudita- de los antiguos etnónimos de Autrigones, Várdulos y Caristios y su suplantación progresiva por el deVascones. Hay un hecho indubitable en todo esto, referido a la etapa tardoantigua en el área, y es el de que, por razones de difícil elucidación, los términos vasco y Vasconia sufren importantes cambios semánticos en el uso que hacen de ellos los autores de obediencia --valga la expresiónfranca o visigoda. De tener un preciso contenido étnico en los autores clásicos, y cubrir un ámbito territorial sensiblemente similar al de la Navarra actual, pasan a designar comunidades humanas y territorios de asentamiento, que exceden en mucho de los antiguos límites, aun habida cuenta de los corrimientos de fronteras que se señalan en relación con los Vascones para los primeros tiempos de colonización romana. Tenemos, así, que, tras una etapa de apariciones más o menos coyunturales en el contexto de hechos bélicos y ope-

\footnotetext{
${ }^{41}$ The coinage of the Visigoths of Spain: Leovigild to Achila II, New York 1952, pp. 85, 18.

42 La precisión cronologica se basarfa en criterios estrictamente numismáticos, segán se hace saber (v. G. C. MILES: lbid.).

43 IOH. BICLARENSIS: Chronica, ad ann. 581 ? (ed. TH. MOMMSEN, p. 216).

44 Los Godos..., p. 86. Esta conjetura le parece justa a M. Rouche (L'Aquitaine... p. 504 n. 10), y es tenida también en consideración por BESGA MARROQUIN, A. (La situación..., p. 29); pero autores anteriores, sobre la fe del testimonio posterior de FREDEGARIO (IV, 5) -que a E. A. THOMPSON (lbid., p. 401 n. 73) le parece "de segundo orden" respecto de los de GREGORIO DE TOURS (Hist. Franc., VIII, 30) y JOHANNES BICLARENSIS (Chronica, ad ann. 585? [ed. TH. MOMMSEN, p. 217])estiman que pudo haber mediado conquista franca de Rosas el 585, en ocasión del ataque dirigido por Gontran contra la Septimania goda y contra España, por lo que juzgan más congruente relacionar la mencionada inscripción monetaria con la teconquista de la ciudad por Recaredo ese mismo año, en ausencia de su padre (asi, MATEU Y LLOPIS, F. De la Hispania tarraconense a la Marca hispánica carolina, in "Analecta Sacra Tarraconensia" 19, 1946, 1-122, concr. p. 13; HILLGARTI, J. N. La conversión de los visigodos: notas criticas, in "Analecta Sacra Tarraconensia" 34, 1961, 21-46, concr. pp. 38ss; ID.: in "Historia" 15, 1966, 503ss).
}

Sobre la Iglesia Medieval

Hispania Sacra 49 (1997) 
raciones de pillaje, que tienen como escenario la primitiva Novempopulania ${ }^{45}$, el etnónimo vascones acaba documentándose hacia la segunda mitad del $\mathrm{s}$. VII ligado a un inequívoco contexto de explotación agraria de la misma ${ }^{46}$. Años antes, en torno al 629, el término Wasconia parece designar, bajo la pluma de FREDEGARIO, no sólo el saltus pirenaico, sino también las civitates novempopulanas $^{47}$. Y vamos a dejar aquí de lado, por tratarse, por to que parece, de procesos algo más tardíos ${ }^{48}$, los casos de equiparación Aquitani-Vascones y Aquitania-Vasconia, que se documentan en ciertos textos de origen franco ${ }^{49}$ y alguno italiano ${ }^{50}$, y que, como los anteriormente registrados, traducen el mismo fenómeno de deslizamiento del etnónimo Vascones -o del corónimo Vas. conia - más allá de los límites clásicos. Estos testimonios, junto a otros varios que apenas costaría esfuerzo acumular, bastan, a nuestro modo de ver, para acreditar de forma plena el proceso de corrimiento que experimenta hacia el Norte el etnónimo Vascones, proceso al que, por cierto, deberá uno de sus nombres históricos el espacio comprendido entre el Garona y los Pirineos. Pero la fortuna del etnónimo vasco a la sazón no se agota en sus espectaculares desplazamientos o migraciones en dirección Norte.

Contemporáneamente, se documentan otros corrimientos semánticos, si bien no tan Jlamativos, por Jas áreas aledañas del antiguo territorio vascón hacia Oeste. Resulta ya sintomático, por una parte, que en Ja documentación tardoantigua se produzcan a cuentagotas, primero, para silenciarse del todo, después, las menciones de las unidades étnicas que las fuentes grecorromanas documentan y sitúan con estimable precisión en los aledaños del primitivo hogar vascón por la banda de Occidente, ocupando los territorios actuales de Alava, Guipúzcoa y Vizcaya y algunas porciones menores de Burgos, Santander y La Rioja. Nada se sabe, así, de los Caristios desde los ya lejanos tiempos

45 Cfr. Gregorius TURonensis: Hist., VI, 12; IX, 7; Fredegarius: Chron., IV, 21. 54. 57. 67. 78.

46 Cfr. Versus de Asia et de Universi Mundi Rota, cc. 28 y 29 (ed. del CC, t. 185, Turnholt 1965, pp. 449s) (v. comentado por M. ROUCHE: L'Aquitaine..., pp. 99 y 511 nota 79).

${ }^{47}$ Chron., IV, 57 (v. comentado por M. ROUCHE: L'Aquitaine..., pp. 90-92).

48 Cfr. Collins, R. The Vaccaei, the Vaceti, and the Rise of Vasconia, in "Studia Historica Historia Antigua" 6, 1988, 211-223, part. 216-221. Para el autor, la ecuación Aquitani-Vascones o Aquitania-Vasconia se documentaría sólo en snales y registros cronísticos de origen franco, referidos a los años entre 731/768 (Annales Sancti Amandi, Annales Nazariani, Annales Mosselani... o los continuadores de Fredegario); por otro lado, el pasaje del Cosmografo Ravenate (v. infra), que la reproduce, derivaría en este punto concreto de informaciones de origen transalpino.

49 V., por ej., FREDEGaRIUS: Contin., 2 [96], 25 [111] y 28 [114] (ed. de B. KRUSCH, pp. 169s, 180s); Annales Nazariani, ad ann. 735 (ed. de G. PERTZ, p. 25); Chronicon Adonis, ad ann. 731 (ed. de G. PERTZ, p. 318)

so Nos referimos al COSMÓGRAFO o ANONJMO DE RAVENA: IV, 40-41. Éste, como se sabe, usa los términos Spanoguasconia y Guasconia como equivalentes de Novempopulania y Aquitania, respectivamente. Sobre datación de la información concernida, v. R. CoLLINS: O. c., pp. 219s.

Sobre la Iglesia Medieval Hispania Sacra 49 (1997) 
de Ptolomeo. Habría tenido que decirse otro tanto de los Várdulos, a no haberse conservado el recuerdo de su nombre en la Crónica de HIDACIO, primero ${ }^{51}$, y --por mero reflejo erudito, según se estima- en una vieja crónica altomedieval, más tarde, aunque referido en este último caso a un marco espacial sensiblemente alejado del de su acreditación primitiva ${ }^{52}$. De los Autrigones, en fin, sólo se hacen eco --y por poco tiempo- unos viejos epítomes geográficos, escritos por autores que viven lejos del área, y que se dirían más interesados en preservar los trazos esenciales de la antigua visión del mundo, que de reflejar los cambios que, por obra de una compleja serie de causas, se están produciendo de un tiempo a esta parte en ese oscuro rincón del mundo ${ }^{53}$.

Ahora bien, parejo a ese proceso de oscurecimiento progresivo de toda una serie de etnónimos y corónimos, manejados por los escritores romanos en relación con las unidades étnicas de la banda occidental del área, se produce otro, no sin relación con aquél - según se estima-, y que se concreta en el deslizamiento progresivo del etnónimo vasco hacia el Oeste, sobre los lugares de asiento de las referidas unidades étnicas de Várdulos, Caristios y Autrigones. La relación sugerida parece apuntar a una dialéctica de desplazamiento o suplantación de los viejos nombres por el nuevo. Es decir, que el silencio de los viejos etnónimos y corónimos no debería ser interpretado simplemente como caída en desuso de los mismos, sino como reflejo de su suplantación por otro en la práctica erudita, en virtud de una compleja serie de causas que habrían de ser analizadas con detenimiento. Hay que reconocer que ese proceso se sigue mejor a través de las crónicas del periodo astur ${ }^{54}$, que a través de las fuentes a remitir a la etapa propiamente visigótica. Pero, en cualquier caso, no faltan en éstas algunos indicadores que apuntan en ese sentido. Está, ante todo, el hecho de que en las muchas o pocas referencias de las fuentes visigodas a los hechos que tienen lugar en la vertiente cispirenaica del área sólo se oye hablar de Vascones (y Cántabros, más al Oeste), cual si la tierra se hubjese tragado a las otras comunidades étnicas. El hecho resistente del Norte peninsular frente a la política unificadora de la realeza visigoda tiene, desde luego, nombres bien conocidos por estos pagos, y responden a los de cántabro y vascón. De resul-

\section{s1 171.}

52 Crbnica de Alfonso $/ I, 14$. No ha faltado, sin embargo, quien en el texto cronístico ha visto la prueba de un corrimiento várdulo hacia el Sudoeste, el que habría sido forzado por la invasión vascona de la depresión vasca: v., así, en este sentido SÁNCHEZ ALBORNOZ, C. Los vascones vasconizan la depresión vasca, en ID.: Vascos y navarros en su primera historia (1975), Madrid 1976, p. 74.

53 Éste parece ser el caso, tanto del Liber generationis (v. en la ed. de K. FRITZ; Chronica minora, v. I, Leipzig 1892, p. 32 [v, asimismo los Excerpta latina Barbari, ed. del mismo K. FRITZ, ibid. pp. 214s]), como - más señaladamente- del ANÓNIMO DE RAVENA (IV, 42).

54 Cfr. Cronica de Alfonso II, 16. 19. 23; Crónica Albeldense, XV, 12 (a relacionar con la Cronica de Sampiro, ed. de J. PEREZ DE URBEL — A. GONZÂLEZ, Madrid 1959, pp. 159s).

Sobre la Iglesia Medieval Hispania Sacra 49 (1997) 
tas, el silencio u olvido de los demás pueblos será interpretado por algunos cual si la vasconización de las provincias así llamadas Vascongadas - $\mathrm{y}$, por supuesto, no sólo a puros efectos de cubrimiento semántico- fuese ya un hecho desde temprana etapa visigótica ${ }^{55}$. Esa especie cobraría grandes visos de probabilidad, si Victoriaco - la nueva fortaleza militar mandada erigir por Leovigildo, tras su ocupacion parcial de Vasconia hacia el 58156 - hubiera que identificarlo con Vitoriano o con algún otro lugar de la llanada alavesa en torno a Gasteiz (Iruña, Armentia, Vitoria misma), según han estimado autores de mucho renombre. Pero, toda vez que las razones para tal identificación se revelan hoy menos perentorias o concluyentes ${ }^{57}$, podemos cuando menos argüir a partir del texto de JULIAN DE TOLEDO, en que a Wamba, disponiéndose a atacar a los feroces Vascones, se lo sitúa in partibus Cantabriae 58 ; o del pasaje de VenanCio Fortunato, en que se hace al Vascón vecino del Cántabro $^{59}$. No se nos oculta que han sido varias y discordantes las interpretaciones que se han propuesto para los fenómenos de corrimiento onomástico señajados, y que contra la tesis de la vasconización política y linguística de la Depresión Vasca, según la formularon A. Schulten, M. Gómez Moreno, R. Menéndez Pidal o C. Sánchez Albornoz, se alzaron voces no menos cualificadas las de J. Caro Baroja y K. Mitxelena, entre otros-- que insistían en el sinsentido de la vasconización lingǘstica y étnica de una zona que, con mejores razones (o, al menos, no inferiores a las de la tesis contraria), cabría afirmar como

ss V., así, SChulten, A. Las referencias sobre los Vascones hasta el año 810 después de J. C., en "Revista Internacional de Estudios Vascos" 18, 1927, 225-40, aquí p. 234; C. SÁNCHEZ AlBORNOZ:- Losvascones vasconizan..., pp. 74-8, efc.

56 IOHANNES DE BIClaRA. Chron., ad ann. 581.

57 Un poco de historia de las identificaciones propuestas, en AZKÁRATE GARAY-OLAUN, A. Arqueología cristiana de la Antigüedad Tardía en Alava, Guipúzcoa y Vizcaya, Vitoria 1988, pp. 495-7, para quien - en contra de los Henao, Flórez, Risco o Schulten, y, más modernamente, los C. Sánchez Albornoz, el equipo A. Barbero y M. Vigil, A. Besga Marroquín, etc.- en manera alguna se justificarian las reducciones que apuntan a la Llanada alavesa, y, siguiendo a J. Caro Baroja y otros autores antiguos (Garibay, Moret, Balparda), propone su ubicación más al Este, dentro del territorio vascón clásico. Para A. AZKÁRATE, la reducción de Victoriaco al ámbito alavés "no deja de ser un supuesto que no reúne, a su favor, argumento alguno, si bien ha servido a unos para justificar una pretendida vasconización de la depresión vasca, y a otros para adecuar el frente antivisigótico a una Euskal Herria de límites geográficos modemos" (Ibid., pp. 509s).

SB Historia Wambae, 9. A no ser que se tratase de la Cantabria riojana de ciertos textos tardoantiguos y altomedievales

59 "Vascone vicino Cantaber iste refert" (Carm., Append. II, 2, vv. 29s [ed. FR. LEO, pp. 276s]). Digamos, empero, que no insistimos demasiado en el valor probativo de textos parecidos, los que, en todo caso, serían el síntoma de las mutaciones que iban produciéndose en el imaginario de los autores cccidentales en lo que a percepción de las realidades del mundo circumpirenaico se refiere. Pero ¿cuales eran las razones que motivaban esas mutaciones en las viejas formas de percepción de esas realidades, o a qué se debían? He ahí el enigma. 
de etria euskaroide ya con anterioridad ${ }^{60}$. Pero lo que, en cualquier caso, nadie cuestiona es que se den esos hechos de mutación onomástica, y que los mismos obedezcan a razones de peso, que probablemente tienen que ver con el nuevo papel que desempeñan los Vascones $\longrightarrow$ los poderes locales que se ocultan bajo tal nombre - en la conducción de la política del área.

Ahora bien, estimamos que el tupido haz de indicios de orden textual, arqueologico y lingüístico, que hemos reunido, proyecta un cuadro conjetural altamente significativo sobre la situación que atraviesa el valle medio y alto del Ebro durante el s. VI, cuadro según el cual el absentismo de los representantes de las iglesias más occidentales de la Tarraconense - y concretamente de la de Pamplona-- a los sínodos de la provincia no sería ya fruto de una casualidad, sino resultado de la débil implantación que tiene a la sazón en el área el aparato de poder visigodo. En la primera mitad del s. VI y aun bien entrado el ́́ltimo tercio del mismo, el peso del aparato de poder visigodo en la zona no es todo lo fuerte y eficaz como para que pueda hacer operativa la institución provincial en los antiguos términos, e imponer consecuentemente (o facilitar en cualquier caso) a los obispos de la misma su asistencia a los sínodos de una iglesia provincial que debe de antojárseles extraña, en cuanto solidaria o sujeta a un poder político extraño. Y es a eso, pensamos, a lo que obedece en última instancia la ausencia de obispos de la parte occidental de la Tarraconense en los sínodos provinciales de la primera mitad del s. VI. Según eso, y en contra de lo que opina el autor ${ }^{61}$, pensamos que sí tiene sentido preguntarse, como lo hace A. Azkarate, "por lo sucedido entre el primer concilio de Tarragona y 581", aunque no tanto porque falte la firma del obispo de Pamplona en las actas conciliares de ese período, sino porque falten las de los representantes de todas las iglesias occidentales de la Tarraconense, además de la del representante pamplonica.

\section{PAMPLONA EN LOS SÍNODOS VISIGÓTICOS POSTERIORES AL 581}

Lo dicho se echa de ver mejor en la respuesta que años después obtienen de los obispos de la zona las convocatorias tanto de los concilios provinciales, como de los generales a partir del III toledano de 589.

so Sobre los términos del debate y la solución que se nos antoja más plausible, v. LARRAN̄AGA ELORZA, K. Euskal Herria Antzinate Berantiarrean eta Lehen Eriaroan. Materiale eta agiriak, Bilbao 1992, sobre todo pp. 19-25; ID.: De "wasco" a "Wasconia" y "Vascongadas". Disquisiciones sobre ciertos corrimientos onomisticos en la Alta Edad Media, en Entre Euskadi y Euskalherria. Vicisitudes de un concepto [m "Langaiak" nn. 8-9, Pamplona 1985], pp. 59-78.

61 O. c., p. 130 nota 28.

Sobre la Iglesia Medieval Hispania Sacra 49 (1997) 
En éste, como se sabe, se hallan representadas todas y cada una de las iglesias de la Tarraconense: trece, mediante titulares, y dos (Ampurias y Tarragona), mediante delegaciones de presbiteros ${ }^{62}$. $Y$ hay que decir que con posterioridad la asistencia a los sínodos, tanto provinciales como de carácter general, es de una cierta regularidad en el caso de las iglesias del área, con la consabida excepción de Pamplona, que sólo se documenta en otras tres ocasiones, cuando Tarazona, la más absentista entre las vecinas, se documenta cuando menos en otras seis.

La interpretación que últimamente venía dándose de estos hechos es que, afirmado en la zona el aparato de poder visigodo -tras las campañas victoriosas de Leovigildo contra Cántabros (h. 574) ${ }^{63}$ y Vascones (h. el 581) ${ }^{64}$ _, por un lado, y superado en cierta forma el clima de recelos, por otro, tras la conversion de Recaredo al catolicismo en el 587, tienden a restablecerse los tradicionales lazos de comunión y subordinación jerárquica, con lo que los obispos -y en concreto, el de Pamplona-- hallan más fácil la asistencia a los sínodos o menos excusable, desde el punto de vista político y eclesiástico, su inasistencia a los mismos. El hecho de la afirmación del poderío visigodo en el área vendría a ser atestiguado a su modo, a la par que por las referencias cronísticas (que hablan — no se olvide_ de la toma de Amaia, y de la fundación de Victoriaco y Ologicus frente a los Vascones ${ }^{65}$, por la existencia de varias cecas que, desde Leovigildo y en los reinados siguientes, se muestran activas en la zona, cubriendo con sus emisiones todo el frente de operaciones militares en que por el Norte se ve envuelto el aparato de poder godo. Ciñéndonos a las localidades más cercanas al área, hay, con posterioridad, constancia de emisiones moneta-

62 Nos servimos para este recuento de la edición crítica de F. RoDRíguEZ (v. Concilio III de Toledo. XIV Centenario 589-1989, Toledo 1991, p. 35), que difiere de la de J. Vives, al incluir al delegado de la iglesia metropolitana.

63 JohANNES BIClarensis: Chron., ad annum 574? [ed. de Th. MOMMSEN, p. 213]

64 JOHANNES BICl.ARENSIS: Chron., ad annum 581? [ed. de TH. MOMMSEN, p. 216]. Sobre el evento, v. supra el texto relativo a las notas 40-44. La campaña que, según ISIDORO (Hist. Goth., 54), condujo Recaredo contra los Vascones se estima debió tener lugar con posterioridad al 589, al no haber sido recogida por Johannes de Biclara, que extiende, empero, a dicho año sus anolaciones cronisticas.

6s Si no resulta fácil localizar el Victoriacum de que habla el Biclarense (v, n. 49), el nombre de Tafalla apunta verosímilmente al punto estratégico en que el poder visigodo debio de instalar una guarnición de caballeros Taifales, en la ruta que desde la ribera del Ebro llevaba a Pamplona (los Taifales, según se sabe, constituían un grupo étnico de estirpe germánica, que en el Bajo Imperio aparece como aliado de los Godos en la Dacia, y del que una parte debió seguir a éstos en sus desplazamientos hacia el Oeste) (cfr. M. RouCHE: L'Aquitaine..., pp. 532s n. 19). La nueva plaza fuerte quedaria, en todo caso, muy cerca del Ologicus u Ologitin que Suintila, tras su victoria de h. el 621, obliga a levantar a los Vascones (ISIDORO: Hist. Goth., 63), si, como se afima comúnmente, hay que relacionar dicho Ologicus con la actual Olite. 
les en Saldaña (Leovigildo, Witerico, Suintila, Chintila, Chindasvinto), Calahora (Suintila) ${ }^{66}$, Tarazona (Recaredo, Witerico, Gundemaro, Sisebuto y Suintila) y Egessa, identificada con Segia o Egea de los Caballeros (Leovigildo, Chindasvinto, Chindasvinto-Recesvinto, Recesvinto, Egica) ${ }^{67}$. ¿Será por caso que, a partir del 589, las iglesias del área empiezan a documentarse con cierta regularidad en los concilios visigodos tanto provinciales como generales (10 asistencias Calahorra, 7 í 8 Tarazona, 869 Huesca, 9610 Oca), siendo así que en la etapa previa no se documentan una sola vez?

Como dicho, la toma en consideración de estos hechos ha empujado a los autores a establecer una cierta relación (¿causal?) entre los mismos y la presencia del obispo de Pamplona en el III concilio de Toledo de 589. Sin embargo, a J. J. LARREA, que cita en su apoyo a J. GoÑI GAZTAMBIDE ${ }^{68}$, nada le parece "más inverosímil que hacer derivar la presencia del obispo católico de Pamplona en el III Concilio de Toledo de la campaña llevada a cabo en algún lugar de Vasconia por el mismo rey que establecerá obispos arrianos en el reino suevo conquistado"69.

Para evitar confusiones (porque puede dar lugar a confusiones el modo en que argumenta a continuación el autor, al señalar que "una comunidad cristiana bajoimperial en Pompaelo es perfectamente comprensible" por diversas razones que alega ${ }^{70}$ ), digamos que es necesario distinguir netamente entre estas tres cuestiones: 1) la del origen del cristianismo en Pamplona, 2) la del origen de una iglesia episcopal en la misma, y 3) la de la presencia del obispo de Pamplona en el III sínodo de Toledo.

En cuanto al primer punto, no seremos nosotros, desde luego, quienes cuestionemos la plausibilidad de la existencia de una comunidad cristiana en Pamplona ya desde el Bajo Imperio, aunque dicho supuesto diste hoy por hoy de estar suficientemente probado ${ }^{71}$. Abogarían, en todo caso, en favor del

66 Hay que ariotar que en la ceca de Calahorra sólo parece haber acuñado Suintila, quien, tras su campaĩa del 621, se emplea, como se sabe (v. n. anterior), en la construcción y acondicionamiento del fuerte de Ologicus.

67 Cfr. MATEU Y LLOPIS, F. Hallazgos monetarios, $H$, en "Ampurias" 6, 1944, aquí 221-225; v. asimismo, el cuadro de cecas y acuñaciones monetarias por reyes, que A. BESGA MARROQUIN incluye en La situación..., pp. 154s. No estará de más, empero, añadir aquí que la acción de las llamadas cecas fronterizas, no menos que del esfuerzo protagonizado por el aparato de poder godo para reafirmar su hegemonía en el área, es reflejo de las limitaciones de su implantación en la misma, al necesitar de constantes inversiones para apuntalar el dispositivo fronterizo frente a los pueblos del Norte.

${ }^{68}$ Historia de los obispos de Pamplona, I: Siglos IV-XIII, Pamplona 1979, pp. 48.52.

69 El obispado de Pamplona.... pp. 128s.

70 lbid., p. 129.

II M. A. MEZQuIRIZ documenta un caso de inhumación de adulto, con orientación Este-Oeste, "en el ámbito sagrado urbano" (de hecho, en el subsuelo de la catedral), lo que estima permite 
mismo, no ya tanto la circunstancia de que se documenten efectivos militares dentro de la plaza (el texto de la epistula Honorii, que ha dado pie a afirmarlo, resulta ya lo suficientemente expresivo en punto a las condiciones del todo peculiares en que se produce el hecho ${ }^{72}$ ), cuanto la realidad de un entorno notablemente cristianizado en el valle del Ebro y en la vecina Novempopulania ${ }^{73}$, $\mathrm{y}$ el hecho de que Pamplona represente un punto crucial en el sistema viario que enlaza la parte occidental de la Tarraconense con la Aquitania.

En cuanto a lo segundo, estamos totalmente de acuerdo con el autor en que "es más que discutible asimilar la ausencia de Pamplona en Toledo a la falta de titular del obispado --más aún, a la inexistencia de éste-'74. Pero somos asimismo de opinión de que admitir la presencia de una comunidad cristiana en la Pompaelo bajoimperial no significa sin más que dicha comunidad o iglesia haya de ser por necesidad de rango episcopal, no siendo raro en los primeros tiempos cristianos el caso de comunidades regidas por presbíteros o diáco$\operatorname{nos}^{75}$. En tal supuesto, y dado que no hay atestaciones de obispos en la ciudad

\footnotetext{
"suponer la existencia de un templo cristiano bajo el actual, en los siglos V-VI d. C." (v. Vestigios romanos en la catedral y su entorno, in La catedral de Pamplona, 1394-1994, [Pamplona] 1994, p. 131). Planteado el tema en términos cronológicos tan holgados y cómodos, apenas habría objeción por nuestra parte para aceptar tal cual las palabras de la insigne investigadora, y menos, si, como se expresa en una comunicación a datar, según parece, en un momento algo posterior (MrzquIRz IRUjo, M. A. y TABAR SARRIAS, M. I. Excavaciones arqueologicas en la catedral de Pamplona, in Trabajos de Arqueologia Navarra, 11, 1993-1994, 310-311), las evidencias delatoras de culto cristiano encontradas en el subsuelo de la catedral se retrasan a "los siglos VI-VII d. C." (p. 311).

72 Se trataría de restos de unidades de tropa, que, en momentos particularmente dificiles y al carecer de lugares de acuartelamiento propios, han de acogerse al derecho del hospitium. Cfr. JoNES, A. H. M. A Letter of Honorius to the Army of Spain, in $X^{e}$ Congrès International d'Études Bizantines. Istambul 1955, Istambul 1957, pp.223ss; ID.: The Later Roman Empire: 284-602. A social, economic and administrative survey, 3 vv., Oxford 1964 (2. ed., Oxford 1973), t. III, p. 36; E. DEMOUGEOT: Une lettre de l'empereur Honorius sur l'hospitium des soldats, in "Revue historique de droit français et étranger" 4, 1956, 25-49; A. BALL: La defensa de Hispania en el Bajo Imperio. Amenaza exterior e inquietud interna, in Legio VII Gemina, León 1970, 601-20, pp. 616-618

${ }^{73}$ Ofrecimos una exposición bastante pormenorizada del proceso cristianizador seguido por el área circumpirenaica occidental en Euskal Herria Antzinntean. Materiale eta agiriak, Donostia 1988, pp. 106-118 y m. correspondientes ( $\mathrm{Pp}$, 176-189).

${ }^{74}$ O. c., pp. $126 \mathrm{~s}$.

75 Lo que, vuelto por activa, viene a decir que ausencia de obispo, más allá de mediados del s. IV, en la capital de una civitas no significa necesariamente que no se dé en ella una comunidad cristiana organizada, la que al caso puede estar presidida por un sacerdos secundi ordinis o un presbyter. Es lo que, comentando un texto de Teodoro de Mopsuestia, observó ya en su día L. DUCHESNE (Fastes épiscopaux de l'ancienne Gaule, t. I, Paris ${ }^{2} 1907$, pp. 37-9) y ha subrayado más modernamente E. GRIFFE, al tratar de explicar el retraso relativo que se observa en el proceso de constitución de las sedes episcopales galas (Les premieres 'paroisses' de la Gaule, in "Bulletin de Littérature ecclésiastique" 50, 1949, 229ss). El concilio de Elvira, a principios del s. IV, avalaría por su lado la
} 
con anterioridad a la presencia de la firma de Lilíolo en las actas del III sínodo toledano de 589, cabría en principio retrasar la erección de una sede episcopal en Pamplona hasta que ésta pasa a manos visigodas, sin que constituya una objeción insalvable en tal sentido lo que argumenta J. GoÑ GAZTAMBIDE, a saber, que eso supondría admitir que Leovigildo, que en su fervor arriano impone obispos de la secta en el reino suevo recién anexionado, entronizase uno católico en la capital de los Vascones ${ }^{76}$; y es que, en rigor, la erección de la nueva sede puede tener lugar tras la muerte de aquél (586), en el breve intervalo de tiempo que media entre la conversión de Recaredo (587) y la celebración del III sínodo toledano (589). En cualquier caso, no deja de ser curioso el hecho de que el único obispo de Pamplona que se persona en un concilio visigodo (y por partida doble, además) sea ese Lilíolo que encabeza justamente las listas del episcopologio iruñés. ¿Hechura del aparato de poder godo? No han faltado quienes lo han visto así, o como "una especie de obispado de campaña puesto [...] por las armas godas en territorio enemigo" - para utilizar la expresión que maneja el autor, referido a diversos autores ${ }^{77}$ - . Nosotros, sin poder afirmarla con razones de índole positiva, nos limitamos a subrayar que tal hipótesis no contradice, que sepamos, nada que se haya argumentado con suficiente base de razones, y que encaja bastante bien en el cuadro de lo que por otro lado conocemos sobre las maneras de los monarcas visigodos en su práctica política ${ }^{78}$ o sobre la historia inmediatamente anterior y coetánea del área.

existencia de esas Iglesias regidas por presbíteros (cf. el proemio de sus actas - ed. de J. VIVES: Concilios visigóticos.... p. 1).

76 O., , I, pp. 48-52.

${ }^{n}$ En concreto, a los J. Moret, A. Campión, J. Caro Baroja, A. E. de Mañaricúa, A. Barbero-M. Vigil, A. Besga, etc. (O. c., p. 124). Ahora bien, al caso podría tratarse tanto de una fundacion ex novo de la sede - por ej., tras la campaña de Leovigildo del 581 - como de restauración de la misma -en el supuesto de que, luego de ser erigida, hubiese quedado largo tiempo abandonada por fuerza mayor (por ej., el control de la ciudad por una facción vascona hostil a la iglesia) - 0 , simplemente, de reposición del titular - caso de que se tratase de ausencias temporales del obispo, impuestas de igual modo por los vaivenes de la política intranuros-, etc. En todo caso, no cabe olvidar que Liliolo es el anteúltimo en firmar las actas del sínodo toledano de 589, y que tal circunstancia lo evidencia como ordenado en fecha reciente, habida cuenta de que el orden de suscripción en los concilios visigodos es justamente el de la antigtiedad en la consagración episcopal.

${ }^{78}$ Nos estamos refiriendo al hecho de que en más de una ocasión se erigen nuevas sedes episcopales en la ctapa visigotica: éste parece ser el caso de Palencia, Osma y Oca, de las que la primera se funda no antes del 531 y las dos áltimas serían de fundación posterior a mediados del s. VI; Este, también, el caso del rey Wamba, reprobado en el c. IV del concilio XII de Toledo del 681 por haberse entregado a nuevas erecciones in [...] vicis vel villulis (ed. de J. VIVES, pp. 389s), sin duda, para consolidar las bases de su propio poder (v. GONZÁLEZ BLANCO, A. El decreto de Gundemaro y la historia del siglo VI, in Los visigodos..., Murcia 1986, pp. 159-69, concr. p. 163). Nos estamos refiriendo, asimismo, a la práctica de la regalia - c. d., a la imposición del nombramiento real como fórmula para acceder al episcopado-, práctica que, aceptada ya como válida - junto a la tradicional elección por clero y pueblo- en el sínodo de Barcelona de 599 (v. canon III led. de J. VIVES, p.

Sobre la Iglesia Medieval

IHispania Sacra 49 (1997) 
Falta que aclaremos el tercer punto. Según nuestro modo de ver, no es en absoluto contradictorio imaginar una iglesia episcopal en Pamplona en los días anteriores a la conquista parcial de Vasconia por Leovigildo (lo que, en cualquier caso, quedaría por probar todavía), y aun así hacer derivar de las campañas militares llevadas a cabo por aquél contra Cántabros y Vascones la presencia del representante de la iglesia iruñesa (y de los de las otras iglesias del área) en el III sínodo de Toledo. Lo que, para J. J. LARREA - presto a admitir, a pesar de todo, que "las presencias conciliares de Pamplona están precedidas de expediciones militares" - vendría a significar "un post hoc, ergo propter hoc particularmente generoso"79. Nosotros-que admitimos, por supuesto, que el post hoc no significa en principio el propter hoc-no vemos, sin embargo, en este caso concreto, las razones que fundamentan las reservas del autor, o no nos parecen tan convincentes las que cimentan su pretensión de que el paralelismo entre las dos series de datos (la de acciones militares protagonizadas por el aparato de poder godo, por un lado, y la de asistencias conciliares,

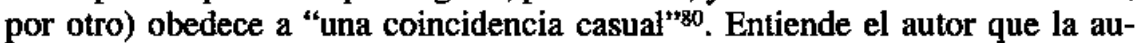
sencia de datos referidos a acciones militares en la etapa comprendida entre la que protagoniza Suintila h. el 621 y la conducida por Wamba el 672 "no es sino el reflejo lógico de la penuria de fuentes cronísticas o históricas en general entre la redacción de la Historia Gothorum isidoriana y la Historia Wambae regis de Julián de Toledo"81. Es posible que eso sea así, aunque, puestos a pensar, cabría igualmente conjeturar que la falta, durante esos años, de una actividad historiográfica parangonable a la isidoriana o a la de Julián de Toledo, es justamente el reflejo de la política vacilante y medrosa de una realeza goda atrapada en sus propias contradicciones, e incapaz de protagonizar hechos como los que llevaron a cabo los Leovigildo, Recaredo, Suintila, etc; porque lo cierto es que no faltan, referidos a ese período intermedio, indicios textuales que sugieren y aun denuncian clamorosamente ${ }^{82}$ aires de tormenta en el ámbito norteño.

Pero admitamos, como pretende el autor, que la ausencia de datos referidos a acciones militares entre los años 621-672 no es sino el reflejo de la penuria de fuentes cronísticas o históricas en general, y no de la falta de respuesta efi-

159]), acaba convirtiéndose en norma a lo largo del s. VII, para ser sancionada en el XII sínodo toledano del 681 (v. canon VI [ed. de J. VIVES, p. 393s]). Cfr. ORLANDIS, J. La Iglesia en la España visigótica y medieval, Pamplona 1976, pp. 90-93.

79 o. c. p. 128. Se observará que en la intención del autor las palabras entrecomilladas no se ciñen al caso de Leovigildo y del III concilio toledano, sino que tienen un alcance más general, en lo que mira a la relación entre acciones militares y asistencia a concilios.

${ }^{80}$ O. c., pp. $129 \mathrm{~s}$

81 O. c., p. 130.

82 V. más adelante el texto relativo a las notas 91-101. 
caz del aparato de poder godo a eventuales brotes insurreccionales en el área norteña. ¿Sería ello razón suficiente para concluir que es pura "coincidencia casual" el paralelismo - en la medida en que se da- entre acciones militares, por un lado, y asistencias a concilios, por otra? Estariamos de acuerdo con el autor, en que "la relación entre las fechas de las campañas [de los reyes visigodos en tierras vasconas] y las de las suscripciones de la sede pamplonesa [en las actas de los sinodos visigóticos] es muy vaga", si, para hablar de relación o paralelismo, fuera preciso que las fechas de unas y otras coincidiesen en rigor. Pero entendemos que un décalage de unos 9610 años entre una operación militar de envergadura, como la que se atribuye a Leovigildo o a Wamba, y la celebración posterior de un sínodo no es razón para que al caso se hable de "relación muy vaga". Y no lo es, porque tales acciones de fuerza llevan aparejadas por lo común otras medidas de tipo estratégico-táctico (reforzamiento del dispositivo de defensa, puesta en marcha del aparato fiscal y administrativo, adoctrinamiento ideológico mediante erección de nuevas sedes episcopales, etc.), que, pensadas para asegurar al acto de fuerza inicial un éxito definitivo, prolongan de hecho el efecto de aquél por una serie de años, hasta que la relación de fuerzas vuelve a ser nuevamente desfavorable. Hoy se admite por lo común entre los autores que la actividad de las así denominadas cecas fronterizas se relaciona tanto con el financiamiento de eventuales operaciones bélicas, como con las necesidades de mantenimiento del dispositivo de defensa y de un elemental aparato administrativo ${ }^{83}$.

Ahora bien, en ese sentido estimamos razonable hablar de relación entre acciones militares y presencias en sínodos, no obstante que entre unas y otras pueda haber algunos años de por medio. ¿Relación causal o relación casual, en definitiva? Tal vez resulte excesivo pretender una relación causal -un propter hoc...- entre acciones militares y presencias en concilios, por lo mismo que la vida de las Iglesias tiene sus ritmos propios y sus márgenes de autonomía. Pero sería igualmente excesivo - $e$ ingenuo-, a nuestro modesto entender, el tratar de ignorar cualquier tipo de relación entre unos hechos y otros; sencillamente, porque, no obstante autonomías y ritmos propios, las Iglesias y más, si se quiere, las Iglesias de la era visigótica - se hallan radicalmente inmersas en el $\alpha \omega v$ secular y participando de sus azares y zozobras ${ }^{84}$. Entre relaciones causales y casuales, un escolástico distinguiría aún otros tipos de

$83 \mathrm{~V}$. infra las referencias de la nota 98.

$84 \mathrm{~V}$, por ej., el canon VI del XII concilio de Toledo, en el que, con anuencia de "todos los obispos de España y de la Galia" (y eso que en dicho sínodo no se halló presente ninguno de la Tarraconense y de la Galia...!), se otorga al obispo de Toledo la facultad de "consagrar prelados y elegir sucesores para los obispos difuntos, en cualquier provincia [...] a aquellos a los cuales la potesfad real eligiere y a quienes juzgare por dignos el mencionado obispo de Toledo" (ed. de J. VIVES, p. 394. El subrayado es nuestro).

Sobre la Iglesia Medieval

Hispania Sacra 49 (1997) 
relación, hablando, por ej., de las que, sin llegar a la causalidad pura, no suponen menos la condición sine qua non para que algo tenga lugar o llegue a materializarse. Pensamos por nuestra parte que algo de eso vienen a ser las campañas de Leovigildo contra Cántabros y Vascones $(0$, mutatis mutandis, la de Wamba contra los Vascones el 672): una condición sin la que muy difícilmente se habría dado la presencia del obispo de Pamplona (y aun la de otras sedes occidentales de la Tarraconense, en el caso de las de Leovigildo...) en el sínodo toledano de unos años después: una condición de posibilidad ${ }^{85}$.

\section{EL COMPORTAMIENTO SINODAL DE LA SEDE DE PAMPLONA Y LA POLÍfTCA ECLESIÁSTICA DE LA PROVINCIA TARRACONENSE}

Convencido J. J. LARREA de que las presencias del representante de la iglesia pamplonesa en los sínodos visigóticos nađa tienen que ver con las acciones de fuerza que protagoniza el aparato militar godo, trata de explicar el comportamiento de la sede en materia de asistencia a sínodos "desde el análisis de la provincia en que está integrada"86. Y en su análisis, halla que "Pamplona suele ir [a los sínodos] cuando toda su provincia [eclesiástica] va, y falta cuando su provincia se muestra reticente a las asambleas toledanas"87. Eso sí, admite que Pamplona falta a los sínodos generales durante una veintena de años (de 633 a 656). Pero se trataría, según el autor, de ausencias que se producen cuando la asistencia de los coprovinciales dista bastante de que sea general: de hecho, según cifras que avanza, la asistencia de la provincia sólo superaría en dos ocasiones la mitad de las sedes existentes y nunca pasaria de los dos tercios ${ }^{88}$.

\footnotetext{
${ }^{85}$ Quede claro que, al hablar así, no damos como probado, según hicimos constar más arriba (v. texto relativo a las nn. 75-78), que la sede episcopal de Pamplona fuese erigida como consecuencia del dominio de la ciudad por Leovigildo, aunque reconozcamos que tal hipotesis no contradice a nada que se haya argumentado con suficiente base de razones, y encaja aun bastante bien en el cuadro de lo que por otro lado conocemos sobre la historia inmediatamente anterior y coetánea del área. Vale la observación -a fortiori- para cuando, al tratar de las presencias del representante de la iglesia iruthesa en los sínodos de 683 y 693, se interpretan éstas como consecuencia del restablecimiento de la sede en la ciudad, tras la acción de fuerza protagonizada por Wamba en el 673. Según el autor (y estaríamos de acuerdo con él en este punto), Jas circunstancias de la campaña de Wamba "encajan mal con el restablecimiento de una sede episcopal" en Iruña (O. c., p. 129). Lo que no obsta a que veamos encajar bastante bien con la figura de Wamba y con su programa de restablecimiento de las bases del Estado visigodo (a eso responđería, en concreto, su política de multiplicación de sedes episcopales [v. GONZÁLEZ BLANCO, A. El decreto de Gundemaro..., p. 163]) una cierta delicada presión sobre el titular de la iglesia pamplonica, tendente a restablecer (o fortalecer) los vínculos (¿cabe decir, harto débiles?) que lo ligaban al Estado visigodo.

86 O.c., p. 131.
8 O.c., p. 135.
\$ lbid.
} 
Al margen de que nuestros datos no coinciden en todo con los del autor (según nuestros cálculos, la suma de iglesias tarraconenses representadas, aun comprendida en dichos cálculos la de Pamplona, superaría con creces la mitad de las existentes en tres de los seis concilios a tener en cuenta —en los de 633, 638 y 653 , en concreto-, y superaría los dos tercios al menos en el de 633, igualándolos en los de 638 y 653$)^{89}$, entendemos que planteamientos así soslayan la verdadera dimensión del problema. No seremos nosotros quienes neguemos que en condiciones de cierta normalidad (?) la iglesia de Iruña pueda participar de los climas de opinión que eventualmente surjan entre prelados y nobles de la Tarraconense ${ }^{90}$, y que su régimen de asistencia a los sínodos pueda verse en alguna medida condicionado por factores de ese tenor. Lo que decimos es que, además de eso, en el caso de la iglesia de Iruña parecen intervenir otros factores que tienen que ver con la peculiar situación que atraviesa el área, y que hace que el pesọ de los referidos climas de opinión a nivel de la Tarraconense resulte aquí menos decisivo o determinante. En el concilio IV de Toledo de 633 se hacen representar 13 iglesias de la provincia -3, entre las 4 más próximas a Iruña (falta la de Oca)-; al VI de 638 asisten 10 de la provincia —entre las que las 4 iglesias más próximas a Iruña-; al VIII de 653, 10 de la provincia, y 3 de las más próximas (esta vez falta Tarazona); entre las 4 únicas iglesias de la Tarraconense, que asisten al $\mathrm{V}$ de Toledo de 636, se cuentan Huesca y Oca. De Pamplona, jni palabra!. Pero, entretanto, hay indicios de revuelo o agitación en el área vascona, a relacionar presurniblemente

${ }^{89}$ El desacuerdo en las cifras ¿se deberá a que el autor empieza su recuento a partir de 636 ? Lo que sea de ello, lo cierto es que en el IV concilio de Toledo, del 633, se hallan representadas trece iglesias tarraconenses, siendo única excepción, aparte de la consabida de Pamplona, la de la iglesia de Oca; que en los concilios V1 y VIIl de Toledo - de 638 y 653, respectivamente- se registran a st vez 10 representaciones tarraconenses, siendo 4, en cada, las que, además de Pamplona, se hallan ausentes; y que sólo en los concilios V, VII y X de Toledo —del 636, 646 y 656, respectivamente (el IX no entra en la cuenta, al ser de carácter provicial) - es baja o muy baja la asistencia (4, 2 y 1 asistencias, respectivamente).

90 ¿Habrá que pensar, así, que Ia inasistencia del representante pamplonés al VI de Toledo de 646 -que coincide, esta vez, con una falta masiva de representantes narbonenses ( 0 asistencias) y tarraconenses (s6lo 2)- responde a una consigna general, que traduciría cl descontento del Nordeste del reino frente a la política de Chindasvinto? Si L. A. GARCíA MORENo (Algunas cuestiones de Historia navarra en la antigüedad tardla (siglos V-VII), in / Congreso General de Historia de Navarra, Pamplona 1987, II, p. 414) tiene todas las trazas de haber acertado, al sospechar alguna razon de ese tipo en la masiva ausencia de tarraconenses y narbonenses entre los firmantes de las actas de ese sínodo (seria, en cierto modo, el síntoma de la revuelta que, conducida por Froya, estallaría clamorosamente hacia el 653), no parece que de ahí se siga que la inasistencia al mismo de una iglesia que, como la pamplonica, practica un absentismo total por esos años haya de ser interpretada como expresión de una misma actitud de protesta compartida. Pamplona, que puede o no participar de la actitud de protesta de sus coprovinciales, no asiste, por la sencilla razón de que a la sazón deja de hacerlo como por sistema. Creo que es ésta la explicación más simple y económica.

Sobre Ia Iglesia Medieval Hispania Sacra 49 (1997) 
con el relajo, que en los momentos finales del reinado de Suintila y de resultas de los desórdenes interiores que abocan en su derrocamiento ${ }^{91}$, parece producirse en el dispositivo de defensa laboriosamente tendido en tiempos anteriores: indicios de revuelo in crescendo, con su clímax en tomo al 653, cuando la rebelión de Froya. Ante todo, se halla un pasaje de una carta de BRAULIO DE ZARAGOZA a Isidoro de Sevilla ${ }^{92}$, a datar por las trazas en una fase avanzada del reinado de Suintila: pasaje en que el obispo zaragozano se hace eco de las angustias vividas en ocasión de una incursión hostil, protagonizada, según se estima ${ }^{93}$, por unos Vascones a los que la campaña del rey de $h$. el 621 no parece haber castigado tan contundentemente como quiere darnos a entender el ditirámbico pasaje de la Historia Gothorum isidoriana ${ }^{94}$, o hace revivir el relajo subsiguiente a los desórdenes interiores que conoce ese momento avanzado de su reinado. Tenemos, luego ( $y$ aun pasando por alto que en el corto gobierno de Chintila [636-639] se registran emisiones de moneda en Saldaña y Mave, justo en el confín cántabro ${ }^{95}$ ), lo que, referido a los días iniciales del reinado de Chindasvinto, revela el epitafio del noble Oppila, muerto por los Vascones en el verano del 642, cuando conducía un convoy de armas a una guarnición del Norte ${ }^{96}$ : noticia, ésta, que halla su complemento en las copiosas

91 Hubo, como se sabe, un vasto complot nobiliario que, encabezado por un tal Sisenando, contó con el apoyo militar del rey franco Dagoberto, poco despues de que éste se hiciese, por muerte de su hermano Chariberto (632), con todo el reino de Aquitania y con Wasconia. No fue necesario que todo el cuerpo expedicionario reunido en Borgoña se personase en el lugar de los hechos: bastó con que los contingentes del Toulousain al mando de Abundantius y Venerandus se presentasen a las puertas de Zaragoza con Sisenando, para que Suintila se viese forzado a la rendición (FrEDEGARIO: Chronica, IV, 73).

92 Epist. III, 1-12 (ed. de L. RIESCO TERRERO: Epistolario de San Braulio. Introducción, edición critica y traducción, Sevilla 1975, p.64).

93 Sobre los problemas de interpretación del pasaje, v. BESGA MARROQUIN, A. La situación..., pp. 39-42, en que se hallarán las referencias bibliograficas básicas.

94 62-63 (ed. de C. RodrígueZ ALONSO, pp. 274-8). Es sabido que el reinado de Suintila registra emisiones de trientes en Saldaña, Calahorra y Tarazona; pero, toda vez que no es posible datarlas con precisión dentro de los diez años de su reinado (621-631), cabría relacionarlas, tanto con la tan celebrada expedición de comienzos del mismo, como con estos momentos más avanzados, a los que remite el pasaje brauliano.

$95 \mathrm{~V}$. referencias de la nota 67 . Cfr., asimismo, MiLE, G. C. The coinage of the Visigoths of Spain: Leovigild to Achila II, New York 1952.

9 Cfr. J. VIVES: Inscripciones cristianas de la España romana y visigoda, 2. ed., Barcelona 1969, п. 287. A. BARBERO -M. VIGILL subrayan el hecho de que la actividad guerrera de Chindasvinto conira los Vascones se haya conocido solo gracias a una inscripción funeraria, lo que, según ellos, vendría a revelar que la información proporcionada en este sentido por las fuentes narrativas dista bastante de que sea completa, dejando abjerta la posibilidad de que otros monarcas que acuifian en la zona hayan también protagonizado acciones bélicas contra los pueblos del Norte (Algunos aspectos de la feudalización del reino visigodo en relación con su organización financiera y militar [1970], en IID.: Sobre los origenes sociales..., pp. 117s). Algo de eso viene a sugerir E. A. THOMPSON, 
emisiones monetarias realizadas por el rey en las llamadas cecas fronterizas del Norte peninsular (Egessa, Saldaña, Mave) ${ }^{97}$, emisiones que, a juicio de autores de prestigio, habría que relacionar con las necesidades de mantenimiento de un dispositivo de defensa peor o mejor estructurado en la zona y los movimientos táctico-estratégicos de los cuerpos de tropa que operan periódicamente en la misma98. Añádase a eso lo que revela de desasosiegos la carta que en el 648 BRAUlio de ZaraGoza, junto con el obispo Eutropio y un tal Celso, escriben a Chindasvinto, solicitándole se asocie en el trono a su hijo Recesvinto, para que con él, en edad "para guerrear y soportar el esfuerzo de las campañas", se "acaben las asechanzas y amenazas de los enemigos y la vida de los leales discurra tranquila y sin temor"99; o lo que, referido a unos pocos años después, narra el obispo zaragozano TAJÓN sobre los desastres que se desatan sobre el valle medio del Ebro por obra de los Vascones que apoyan la rebelión de Fro$\mathrm{ya}^{100}$. Indicios, todos ellos, que delatan que, desde el segundo cuarto del s. VII

cuando subraya la forma totalmente incidental como liega hasta nosotros la noticia de otros sucesos relevantes de orden bélico (Los Godos..., p. 184).

$97 \mathrm{~V}$. referencias de la $\mathrm{n} .95$

98 Sea lo que sea lo que haya de pensarse de la cuestión del limes hispánico, parece hay acuerdo entre los autores sobre que la actividad de esas cecas fronterizas debe relacionarse con las necesidades de financiamiento de esas campañas repetidas periódicamente, o la de mantener un cierto dispositivo de vigilancia en zonas que se han revelado potencialmente peligrosas (cfr. BARBERO, A. - VIGILL, M. Algunos aspectos..., pp. 114-18; GARCÍA MORENO, L. A. Imposición y política fiscal en la España visigoda, in Historia de la Hacienda española (épocas antigua y medieval), Madrid 1982, 263-300, aquí 278-280; el mismo BARCELÓ, M. La cuestión del limes Hispanicus', in "Acta Numismatica" 5, 1975 , p. 33, muy crítico, por otro lado, con la cuestión del limes).

99 Epist., XXXVII (ed. cit. de L. RIESCO TERRERO, p.148) (v. al respecto A. BESGA MARROQUIN: $L a$ situación..., pp. 55-7, en que se hallarán las referencias hermenéticas precisas). Conviene no olvidar, por otro lado, que la corregencia de Chindasvinto y Recesvinto (649-653) se ser̂́ala por alguna emisión de trientes en Egessa (cfr. referencias de la n. 94).

100 Epistola ad Quiricum Barcinonensen antistitem, 2 (en M. RISCO: La Vasconia, tratado preliminar a las santas Iglesias de Calahorra y de Pamplona, t. 32 de la España Sagrada [1781], Madrid2 1878, p. 172). El texto de Tajón vendría a tener un correlato, según entiende M. C. DíAZ Y Díaz (Noticias históricas en dos himnos liturgicos visigodos, in Los Visigodos..., 443-56), en un viejo himno litúrgico de autoría desconocida —el Ymnus de profectione exercitus qui usque in reuersione dicendus est diebus letaniarum (= C. BLUME: Hymnodia Gothica. Die mozarabischen Hymnen des alsspanischen Ritus [Analecta Hymnica Medii Aevi, XXVII], Leipzig 1897 [Frankfurt 1961], pp. 269-271)-. himno que habria que datar, por las trazas, en los días del correinado de Chindasvinto y Recesvinto. Alli donde en el himno se ruega al Sefior que su pueblo gentes barbaricas cornibus uentilet / ac planta terat inpios, o que non nostris noceat pugio finibus, etc., detecta el autor alusiones a la sublevación de Froya y "a la violenta y extensa ocupación por parte de los vascones de una buena zona de la región del Ebro hasta llegar al asedio de Zaragoza" (pp. 447s). Parece también relacionarse con los dificiles momentos que atraviesa el valle del Ebro en ocasión de la rebelión de Froya el Carmen XX ("Hymnus in pacem") de EUGENIO DE TOLEDO (ed. de F. VOLLMER, in $M H H, A A, X I V$, pp. 247s). Obispo de la sedes regia entre 646 y 657, pero, con anterioridad y en los dfas de Braulio archidiácono de la iglesia de Zaragoza $\mathrm{y}$, sin duda, testigo directo de las angustias que vivió ésta en 
y en las décadas siguientes, la situación del área dista mucho de que pueda decirse de normalidad - al menos, para quienes se sienten súbditos leales del rey toledano--, y dan pie a que en la inasistencia de los obispos de Pamplona a los concilios generales de 633 a 656 se sospeche el síntoma de "una situación de independencia de aquelios territorios"101.

\section{LA IGLESIA DE PAMPLONA EN LOS ÚLTIMOS SíNODOS VISIGÓTICOS}

La iglesia de Pamplona se hace representar en los concilios toledanos XIII y XVI (de 683 y 693, respectivamente), y lo hace mediante un diácono llamado Vincómalo. En cambio, no está presente en el XII concilio del 681, al que tampoco asiste representante alguno de la Tarraconense, ni de la provincia de la Galia, y falta también al XV concilio dẹ 688, en el que sí hay representación masiva de iglesias tarraconenses (Huesca, única ausente, además de Pamplona): ausencias y presencias del representante iruñés, cuya clave habrá de ser buscada, según quiere J. J. LARREA, en el comportamiento solidario que mantiene la provincia tarraconense, junto con la de la Galia, en todo el oscuro proceso que antecede y sigue a la rebelión de Paulo đel 673. El comportamiento particular de estas dos provincias - puesto ya de relieve, segán quiere alguno, en la inasistencia masiva de representantes de las mismas en el VII concilio general del 646, como forma de protesta por las medidas antinobiliarias de-

ocasión de las incursiones hostiles a que se refieren los textos arriba citados de aquél (v. supra, junto con el comentario pertinente de E. A. THOMPSON [Los Godos..., pp. 193s y 226s]), Eugenio habla, en su himno, de los males que azotan a la plebe cristiana, pero lo hace en un tono en el que uno creería escuchar a ratos el eco de las palabras del obispo Tajón en su vívida descripción de la invasión vascona del afio 653: "[...] (Frustrantur urbes) his repletae civibus / (Cladesque maer)ent bestiarum fletibus / (Lupis et atris quod prae)bentur vulpibus. / (Gravis fortuna nos) misellos opprimit / (Turbis ubique territ)amur ethnicis / (Templaque sancta nunc) dicantur idolis / [...] Kaptis amicis et perustis praediis / Deum precemur corde cum suspiriis, / Ut curvet hostes et resistat improbis / [...] pacem rogamus, pacis infer copiam; / favore pacis gens quiescat barbara / [...]". Fijese en lo de "turbis ubique territamur ethricis" o en el "templaque sancta nunc dicantur idolis", etc. Hemos de anotar aquí que las - partes entre parentesis de este himno abecedario son supplementa anjadidos por el editor, según se encarga de avisar el mismo en nota. Para el comentario del himno, cfr. BEl TRÁN TORREIRA, F.-M. El concepto de barbarie en la Hispania visigoda, in Los Visigodos..., pp. 53-60, part. 58, quien presenta, empero, varias erratas en la transcripción del texto. En fin, se hace eco de la incursión vascona, unos cien años despues, el autor de la Chronica muzarabica, en cuyo relato, empero, por un increíble proceso de reducción de la memoria histórica, desaparece hasta el nombre de Froya, para cifrarse todo en una incursatio Uasconum que, por las trazas, debió de causar una impresión terrible en las gentes de la época (Chronica muzarabica, 21 [- Continuatio Hispana o Anónimo de Córdoba], ed. de J. GIL, I, p. 24). Hay que anotar, por último, que el reinado en solitario de Recesvinto (653-672) se sefiala por una emisión monetaria en Egessa.

${ }^{101}$ Así, recientemente, GARCiA Moreno, L. A. Historia de España Visigada, Madrid 1989, p. 164. 
cretadas anteriormente por Chindasvinto ${ }^{102}$ - se cifraría en su ausencia total en el sínodo XII del 681 (en el que, como se sabe, a cambio de notables concesiones a nobles y obispos, Ervigio obtiene la legitimación de su designación al trono, tras la rocambolesca puesta en escena de la penitencia de su antecesor Wamba) y en su asistencia masiva - pero mayormente ${ }^{103}$ mediante delegaciones de rango abacial, presbiteral o diaconal- en el XIII de 683 (el que, con la concesión del perdón a los represaliados desde la rebelión de Paulo y aun desde los días de Chintila, y mediante otra serie de favones a la nobleza, viene a cerrar, de alguna forma, la crisis abierta con la política centralista o, si se quiere, antinobiliaria de Chindasvinto y Wamba, y devuelve las cosas a la normalidad). De hecho, en el XV sínodo del 688 o en el XVI del 693 las iglesias de la Tarraconense y demás provincias se hacen representar con generosidad, excepto la Narbonense, la que, empero, puede justificar sus ausencias -al menos, para el caso del sínodo del 693- por el rebrote de una epidemia de peste bubónica ${ }^{104}$.

Siendo presumiblemente las cosas así, no dejaría de ser menos cierto que las presencias de Pamplona en esta nueva fase de su historia sinodal -dos presencias, las dos mediante delegado diácono- vienen precedidas de una expedición militar (673) y, sobre todo, de una acción de gobierno - la de Wamba (672-680) - que se caracteriza justamente por las enérgicas medidas que pone en ejecución para consolidar las bases económicas de su propio poder y los mecanismos de defensa del reino contra los enemigos exteriores e interiores. Se señalan, en ese sentido, una especie de ley de servicio militar, que obliga, en determinados supuestos y bajo penas gravísimas, a obispos y eclesiásticos de cualquier grado, así como a la nobleza laica, altos dignatarios del reino y toda persona que se halle en el lugar de una eventual alarma o dentro de las 100 millas de aquél, a acudir a la llamađa de los jefes militares de la zona con las clientelas de hombres armados que hubienen a su servicio; asimismo, la creación de nuevos obispados - como instrumentos de control del territorio, se supone ${ }^{105}$ - aunque nada se sepa de actuaciones en tal sentido,

302 Cfr. GARCía MORENO, L. A. Algunas chestiones de Historia navarra en la antigüedad tardia, in 1 Congreso General de Historia de Navarra, Pamplona 22-27 de septiembre de 1986, v. II: Comunicaciones: Archivistica, Prehistoria, Edad Antigua (= "PV" 48, Anejo 7, 1987), Pamplona 1988, pp. 147.160, aqui 414; ID.: Historia de Espafta..., p. 165.

${ }^{103}$ Sólo dos obispos de la Tarraconense - los de Oca y Tonosa-, más otros dos de la provincia de la Galia - los de Béziers y Magalona - asistieron personalmente a Toledo.

104 Concilio XVI de Toledo, Lex edita in confirmatione concilii, ed. de J. VIVES, pp. 515s. Es sabido que Pamplona se halla presente en este último mediante el diácono Vincómalo representando al obispo Marciano (ünico caso de delegación en la Tarraconense para esta ocasión), sin que, empero, se haga representar -única excepción junto con Huesca- en el XV del 688.

105 V. supra referencias de la nota 78. 
por lo que hace en concreto a la Tarraconense ${ }^{106}$. Estando así las cosas, y careciendo de ulteriores informaciones sobre asistencia de obispos a los dos últimos concilios de la etapa visigoda (el XVII del 694 carece, como se sabe, de nómina de asistentes y el XVIII de hacia 703 , de actas), tan plausible resulta creer que la presencia de la iglesia pamplonica en los concilios del 683 y 693 - o su ausencia en el de 681 - se debe sólo a su perfecta sintonía con las demás de la provincia en cuestiones de interés general, como creer que, a despecho de eventuales sintonías entre la iglesia inunesa y demás coprovinciales, las presencias de aquélla no se hubiesen producido, de no haber mediado la enérgica acción militar y gubernativa de Wamba. En este supuesto, y según decíamos arriba, la superestructura militar visigoda intervendría como condición

106 A no ser que se quisieran tomar como fundaciones de Wamba las sedes de Alisana, Amaia y Segia, registradas como sufragáneas de la Tarraconense en un viejo Nomina sedium episcopalitun de origen cordobes y, parciaimente, en otras dos Divisio áltomedievales (registradas, Amaia y Segia, en la Divisio que atribuye a Constantino el mozárabe toledano autor de la Pseudo-isidoriana led. TH. MOMMSEN, in $M G H, A A, X I$, p. 382], y Amaia, nuevamente, en la que reprodujo Al-Bakrî, geбgrafo hispano-musulmán del s. XI led. É. LÉvi-PROVENÇAL, in La péninsule ibérique du Moyen Age d'après le Kitâb Ar-Rawd..., Leiden 1938, pp. 247-9])-.. Pero es sabido que C. SÁNCHEZ ALBORNOZ - para quien el Nomina cordobés sería el resultado del ensamblaje de una matriz del último tercio del s. VI con un "arquetipo antiquísimo, quizás previsigodo"- sitúa en una etapa previsigoda la fundación de dichas sedes, a las que, por otro lado, ve desaparecer tempranamente (así, en Fuentes para el estudio de las divisiones eclesiásticas visigodas [1930], in ID.: Investigaciones y documentos sobre las instituciones hispanas, Santiago de Chile 1970, 66-107, partic. 94-107; item en Sobre las "Nominae sedium episcopalium" visigodas [1946, con unos Addenda de 1970], Ibid., 108-113, en que responde a las reservas de L. VÁZQUEZ DE PARGA, fundadas básicamente en que la presencia de las citadas sedes en el Nomina cordobés se debe a un añadido posterior [v, La división de Wamba. Contribución al estudio de la historia y geografía eclesióstica dela Edad Media española, Madrid 1943, pp. 13-22], y de P. DAvID [Études historiques sur la Galice et le Portugal du VIe an XII siecle, Lisboa-París 1947, pp. 1-4]). Así las cosas, a nosotros sólo nos resta señalar que las razones esgrimidas por C. S. A. para remitir a la ctapa previsigoda la fundación de Segia —valga por caso-, no resultan todo lo concluyentes o decisivas que se quisieran: la sede citada - recuerda - no figura en buena parte de los manuscritos que han conservado la Hitación; sus prelados nunca concurrieron a los sínodos toledanos; y no se hace mención de ella entre las erigidas por Wamba, que suprimió el concilio XII de Toledo. Ahora bien, si uno se hace cargo de que las actas de este concilio dan pie a sostener que pudo haber habido otras fundaciones de sedes in (...) vicis vel villulis (ed. J. VIVES, pp. 389s), que las que se mencionan explicitamente cono fundadas por Wamba; que los titulares de esas supuestas sedes no tuvieron ocasión de personarse en ningún sínodo, porque en los días de su supuesto fundador no hubo concilio general alguno, y al primero que se convoco tras su abdicación $-\mathrm{y}$ decretó la supresión de las nuevas sedes, el toledano del 681 - faltaron las provincias de Tarragona y Narbonense en bloque, sólo quedaría en pie - de las razones apuntadas- la que tiene que ver con la ausencia de menciones de la sede en buena parte de los manuscritos que han conservado la Hitación de Wamba, lo que, habida cuenta de que "la serie de las sedes metropolitanas y episcopales que la Hitación registra coincide con la que resulta de las suscripciones de los obispos a las actas de los concilios de Toledo" - -según reconoce el mismo C. S. A. (Fuentes..., p. 89)-, no se nos antoja argumento tan decisivo conno para excluir de raíz el que fuesen las de Segia y Alisane, por ej., algunas de esas fundaciones in [...] vicis vel villulis que se le achacan a Wamba (v. referencias de la nota 75 ). 
que hace posible al obispo de Pamplona la reafirmación de los lazos de comunión con los demás obispos de la provincia y de todo el reino.

Es lo que, si no hemos entendido mal, resulta menos admisible para J. J. LARREA. En su demostración parte de una peculiar lectura de los hechos que configuran el affaire del dux Paulus.

\section{LA REBELIÓN DE 673 Y LA PARTICIPACIÓN VASCONA EN LA MISMA}

El autor se aparta de las lecturas al uso ${ }^{107}$ en puntos importantes. Estima, ante todo, que el ataque de Wamba a los Vascones en el 673 - tanto si se admite que con anterioridad hubo señales de inquietud entre éstos, como si noobedece a una estrategia global de acoso y cerco del movimiento sedicioso surgido en la Septimania en la primavera de dicho año. Entiende el autor que la agitación vascona formaba parte del plan ideado por los sediciosos para derrocar a Wamba, y que éste estuvo informado de todo desde primera hora y, por supuesto, con anterioridad a su marcha a Cantabria, para preparar el ataque a los Vascones. Alli, según el autor, de lo que se enteró Wamba fue de la traición de Paulo, e. d., de que, lejos de aplastar el movimiento sedicioso --según se le había encargado-, éste se había puesto del lado de los rebeldes, y estaba esperando su ocasión para venir a España y luchar por la corona. J. J. LARREA ve en la expedición de Wamba contra los Vascones del año 673 "el precedente de la altima campaña visigoda en Vasconia: cuando, tras la elección de Rodrigo, la aristocracia tarraconense y septimana se alinea con la familia de Witiza y Agila se proclama rey, Rodrigo calca la decisión de Wamba y ataca el territorio vascón"108. Con todo lo cual quedaría probada, según estima el autor, "la conexión de la Vasconia peninsular con la revuelta general del Nordeste del reino"109.

Subrayar lo de peninsular ha sido idea nuestra, y viene a cuento de que a $J$. J. Larrea no le place en absoluto que, en razón de la intervención del dux Lupo y sus Vascones en la conjura"10, se piense en algo así como una "participación conjunta de vascones de ambos lados de los Pirineos"1". Es decir que, para el autor, la Vasconia peninsular se comporta en todo el affaire -al igual que en

107 Cfr., entre otros, Thompson, E. A. o. c., pp. 251-58; García MORENo, L. A. Historia de Espafia..., pp. 171s; BESGA MARROQUIN, A. La sitwacion..., pp. 44-46; ROUCHE, M. L'Aquitaine..., pp. $102 \mathrm{~s}$, de los que alguno, empero, parece aproximarse en ciertos detalles a los puntos de vista expuestos por el autor.

108 O. c., p. 139.

109 O. c., p. 140.

110 Cfr. S. JULIÁN DE TOLEDO: Historia Wambae regis, 8 y 27-28.

11 Ibid., p. 138 nota 56, en que marca sus distancias frente a A. Azcárate, autor de las palabras entrecomilladas. 
el de la conjura de Froya ${ }^{112}$, por otro lado- como una porción más del reino godo, tal Lérida o Barcelona: respondiendo a unos mismos imperativos de grupo o moviéndose por la fuerza de unos mismos antagonismos, que enfrentan a aristocracia y realeza o a los varios bloques de intereses que pugnan entre sí. Nada, en cambio, advierte en el comportamiento o actitudes de sus gentes, que disuene de lo que a la sazón se da en otras latitudes, y que obligue a definir el hecho vascón como algo peculiar o irreductible. En este sentido, todo lo que viene a decir el autor a seguido, bajo el epígrafe Historiografia y retóri$c a^{113}$, se reduce a hacer creer que el modo distinto en que aborda Julián de Toledo $-\mathrm{y}$, con él, otras fuentes anteriores y posteriores- "lo relacionado con aquella tierra" (porque se advierte que el mismo "difiere del que utiliza para referirse a los demás escenarios y protagonistas del conflicto") es sólo cuestión de retórica. "Simplificación del papel de los vascones y aplicación a éstos de un cliché literario: un doblete - dice- que es moneda corriente entre autores hispanos y francos".

No es que vayamos nosotros a negarle que sea una realidad en la obra literaria lo de las simplicaciones-reducciones o lo del uso de estereotipos y clichés. Si no constaran de mil modos tales prácticas, los casos que cita, referidos a nuestro más inmediato Spätantike, bastarían en su ejemplaridad para demostrarlo. Lo que pasa es que todo cliché literario, fundado por lo común en la convención social, responde a las necesidades o conveniencias expresivas de un grupo, como responde a las necesidades expresivas del mismo el que el término pan, fundándose asimismo en una convención social, signifique lo que significa y no otra cosa. Ahora bien, ¿qué es lo que se quiere decir, cuando se afirma que en el caso de los Vascones lo de la ferocidad es un tópico? ¿Que el mismo no responde ya a la realidad de los hechos, ni cumple una necesidad expresiva, porque los Vascones - que fueron quizá feroces alguna vez- dejaron de serlo? $\mathrm{O}$ ¿hay que pensar que lo de feroz es tópico ya desde un principio, $y$ hay que interpretarlo bajo otro prisma? ¿Tal vez como el intento reiterado de un colectivo social por estigmatizar comportamientos que, estimados quizá gallardos y generosos, referidos al propio grupo, son tildados de feroces o bestiales, cuando se trata de otro? En cuyo caso, naturalmente, dicho cliché respondería a otra necesidad expresiva, que podría ser muy bien la de acotar y neutralizar semánticamente, demonizándolo, un colectivo humano que es sentido como nocivo o potencialmente peligroso para la seguridad del propio... $Y$ es que ¿qué quiere decir que San Julián, refiriéndose a las Vasconum gentes, utilice la expresión feroces —como algunos años antes TAJóN ${ }^{114}$ usa lo de

112 V. ibid., p. 139 nota 59.

${ }_{113} \mathrm{Jbid.}$. pp. 140-144.

114 Epistola ad Quiricum Barcinonensen antistilem, 2. 
gens effera Vasconum -, o que ISIDORO, tratando de caracterizar a los Vascones a los que combate Suintila115, eche mano del montivagi populi, acordándose, si se quiere, de que VEN. FORTUNATO usa también alguna vez el término vagus, en referencia al Vascón que puebla las alturas pirenaicas ${ }^{16}$ ? ¿Meras servidumbres o inercias literarias, sin ulteriores anclajes con la realidad? ¿Se quiere dar a entender que ya no tiene sentido lo de Vacceos invictos a nulla gente obtentos de una glosa temprana de las Etimologías ${ }^{117}$, o que no significa nada lo que las mismas fuentes hispanogodas han retenido de la larga historia de enemistades y desencuentros, que caracteriza la relación entre Godos y Vascones? Porque de lo que no cabe duda es de que éstos son percibidos como tradicionales enemigos de aquéllos y no como meros súbditos levantiscos de] rey: así, el mismo JULIÁN, cuando presenta a los diversos agentes que intervienen en el complot de Paulo, distingue entre los sediciosos, perfidiae socios de aquél, y las Francorum Vasconumque multitudines, que, prolatis promissisque muneribus, se compra el $d u x$ para que lo apoyen en su intentona ${ }^{118}$. Y que conste que nada tenemos que objetar a lo que, a título conjetural y contra la versión de autorizados intérpretes, aventura J. J. LARREA sobre que la campaña de Wamba contra los Vascones, motivada tal vez por síntomas de agitación previos de los mismos, responda a un plan global de acoso y aplastamiento de los conjurados, que está ya diseñado antes de ponerse en camino para Cantabria $^{119}$. Lo que, en cualquier caso, no estaríamos tan dispuestos a admitir es

\footnotetext{
115 Hist. Goth., 63.

116 Carm., X, 19: Ad Galactorium Comitem, vv. 11 s.

$117 \mathrm{IX}, 2,107$. De objetársenos que en el pasaje transcrito hay que ver muy probablemente una interpolación del texto isidoriano (así, la ed. de W. N. LINDSAY lo recoge sólo en nota, adscribiéndolo al codex Toletanus ${ }^{2}$, cabría responder que la alteración derivaria, en todo caso, de fecha tempranisima, a referir presumiblemente a los primeros affos del segundo cuarto del siglo VII, y que, de esa forma, sería expresiva de estados mentales de ciertos círculos de la intelectualidad hispanogoda de la época, menos obligados que Isidoro a los dictados de una historia oficial. Las precisiones cronológicas las debemos a una comunicación verbal de $\mathrm{M}$. C. Díaz y Díaz, a quien agradecemos vivamente desde aquí sus atinadas observaciones. Segin este eminente conocedor de la literatura hispanogoda, el inciso en cuestión vendría a constituir una de las adiciones que entre 628 y 630 hizo Braulio de Zaragoza al texto de las Etimologias, adiciones que luego vendrian a confluir en los códices de la denominada por Lindsay familia hispanica sive interpolata (codices $\mathrm{T}, \mathrm{U}$ y $\mathrm{V}$, en concreto, de los que el T(oletanus] dataría de principios del s. IX y los otros dos, de hacia mediados del mismo siglo). De lo que, en todo caso, estaba mucho menos seguro don Manuel es de que bajo el Vacceos del texto hubiese que entender a los Vascones.

118 Historia Wambae regis, 8.

119 O. c., pp. 138-40. Como a argumento de fuerza, recurre al Iudicium in tyrannorum perfidia promulgatum, escrito por el mismo Julián en el 673, y que contiene un breve sumario de los hechos, más exacto incluso que el relato - de mayores vuelos, pero algo posterior también-- de la Historia Wambae (según el reciente estudio de GARCía LÓPEZ, Y. La cronología de la 'Historia Wambae', in "Anuario de Estudios Medievales" 23, 1993, 121-139, aquélla habría sido escrita años después, h. el 681, en los difíciles momentos que siguieron a la deposición de Wamba en el 680 y el advenimiento
}

Sobre la Iglesia Medieval Hispania Sacra 49 (1997) 
que los Vascones intervengan en el conflicto al mismo título que los secuaces del $d u x$ de la Tarraconense Ranosindo, o los del comes de Nîmes, Ilderico: simplemente, porque en el caso de los primeros - lo mismo que en el de los Francos [Aquitanos] de Lupo, que se mencionan en diversos momentos del relato de JULIÁN ${ }^{120}$ - se trata de agentes exteriores que, por dinero o atraídos por otras ventajas, ayudan al buen éxito del complot, mientras que en el de los segundos nos las habemos con fieles del rey visigodo, ni más ni menos. $Y$ decimos esto, porque nada en las fuentes coetáneas -referido a los días de Isidoro, Tajón o Julián-empuja a ver a los Vascones como súbditos leales del rey de Toledo, que, en momentos de obnubilación y por razones más o menos especiosas pero siempre de política interior, se alzarían contra su señor (tal Sunna, Froya o Paulo), sino más bien como enemigos tradicionales de la patria christiana -que diría Tajon-, que, en determinados momentos y por intereses espúreos, pueden ser llamados por los malos súbditos del rey a intervenir en asuntos de política interior --así, Lupo y sus Francos [vasco-aquitanos]-.

No nos atreveríamos a afirmar un comportamiento similar en los obispos de Pamplona, por la sencilla razón de que no sabemos otra cosa sobre ellos, sino que asisten a unos pocos concilios visigóticos. Pero, visto lo que sucede en la vecina Novempopulania, no nos repugnaría ni un ápice la hipótesis de jefes de la comunidad cristiana pamplonesa, proclives a entenderse con los jefes locales que se resisten a la dominación visigoda, para labrarse su propio espacio de poder. Si pilla demasiado lejos el caso del obispo Amelius de Tarbes, implicado en oscuros complots con el $d u x$ franco Bladastes en los días de Gontrán y Leovigildo ${ }^{121}$ (al afin y al cabo, Bladastes es un funcionario neustrio, no obstante que por las razones que sea busca abrirse su propio espacio de poder en

de Ervigio el afio siguiente). Pues bien, del resumen de hechos que ofrece el Iudicium se deduciría que la decisión de aplastar la rebelión septimana está tomada antes ya de ponerse Wamba en camino para Cantabria: "[...] es imposible in Tarraconensem provinciam accedere -arguye el autor, comentando el texto- - desde Vasconia, Cantabria, Calahorra o Huesca" (p. 140). Y así es. Ś́lo que, puestos a exigir rigor, cabría exigirselo también a ISIDORO, que habla de incursiones de los Vascones en la provincia Tarraconense (Hist. Goth. 63). Pero ges que, en rigor, cabe desde Vasconia hacer incursiones en la Tarraconense? $O_{\text { }}$ será que en el horizonte mental del hispalense la Vasconia de los Vascones problemáticos (los únicos, por otra parte, que asoman a las fuentes, hasta el punto de que se apropian del nombre y éste suena igual a discolo o enemigo de la patria cristiana) había dejado de asociarse con la Tarraconense clásica?

${ }^{120}$ Historia regis Wambae, 8, 27, 28

121 Cfr. GRBo. TUR.: Hist., VIII, 28. - Sobre el sentido de la aventura politica del obispo Amelius - a situar en el contexto de una Aquitania bien relacionada con la vertiente cispirenaica, por un lado; cansada de guerras entre los merovingios, y dispuesta a jugar sus bazas para ascegurarse su propio espacio de poder frente a los amos del Norte, por otro-, cfr. DELARUELLE, É. Le diocese de Bigorre dans I Pespace franc de 506 a 587, en Gens et choses de Bigorre, [Saverdum] 1967, pp. 20-28. 
el entorno circumpirenaico ${ }^{122}$ ), tenemos a Palladius y su hijo Sennocus, coepíscopos de la sede metropolitana de Elusa (Éauze) a despecho de todas las disposiciones conciliares, quienes hacia el 626 son condenados al exilio, bajo la acusación de haberse aliado con los Vascones, enemigos de los Francos ${ }^{123}$. Años más tarde, coincidiendo en el tiempo (673/675) con los esfuerzos que protagoniza Wamba para reforzar su poder, se reúne en St.-Pierre-de-Granon, sobre el Garona, el llamado sínodo Modogarnomense o Burdigalense, sínodo, que, contra lo usual en la Iglesia gala, se celebra por vez primera en presencia de laicos y bajo la presidencia del dux Lupo —mediante viro inlustri Lupone duce - , siendo correspondida la convocatoria con una generosa asistencia de prelados novempopulanos ${ }^{124}$. ¿Hará falta recordar que, en tal ocasión y no obstante mantenerse "una fachada oficial merovingia"125, Lupo representa de hecho ante los provinciales Acutani la opción de un poder regional y local, aligerado de coyundas respecto de los bárbaros del Norte y aliado con el Vascón del Sur? Por otro lado, el sínodo Modogamomense constituiría, a nuestro modo de ver, el reflejo de un viraje decisivo en los destinos de la Iglesia novempopulana, viraje que vendría a determinar el punto de arranque de una nueva dialéctica, más conciliadora y abierta, en las relaciones entre Iglesia y mundo vascón ${ }^{126}$.

Algo que no debiera olvidarse en todo este asunto es que el ministerio episcopal, concebido en principio como servicio para la $\varepsilon \kappa \kappa \lambda \varepsilon \sigma L \alpha$ o congregación de los creyentes, sufre profundas hipotecas - como cualquier otro instituto en manos de los hombres- como precio por su adaptación a las nuevas realidades historico-culturales, y que en un horizonte como el del Spätantike, en el que la ruina del Imperio de Occidente determina la desaparición de las grandes carreras al servicio de la administración y la regionalización de la base económica de las grandes fortunas senatoriales de antaño, el ejercicio de la función episcopal se convierte en formidable instrumento de poder y dominación ${ }^{127}$,

122 Cfr. Rouche, M. L'Aquitaine..., pp. 88 y 504 (notas 11-13).

123 Fredegarius, Chron., IV, 54 (ed. B. KRUSCH in en MGH, SRM, II, Hannover 1888, p. 148).

124 Nueve asistencias, sobre once posibles (faltan Dax y Bigorre). A título comparativo, en el concilio de Clichy del 627 -el último anterior, cuyas actas registran la procedencia de los obispos asistentes- sólo estuvieron presentes dos: el obispo Audericus de Auch y el metropolitano de Elusa Senotus (sin duda, el "traidor" Sennocus o Sidochus de la noticia de Fredegario, de que es cuestión en la nota anterior, el que - síntoma evidente de la impotencia del rey Clotario Il ante las fuerzas de desagregación del reino..., comentaría M. Rouclie- había vuelto ya del exilio al que había sido condenado pocos meses antes [L'Aquitaine..., pp. 89s]).

125 ROUCHE, M. L'Aquitaine..., pp. 100s.

126 Cfr. LARRAN̂AGA ElORZA, K. Euskal Herria Antzinate Berantiarrean.., pp. 200-202.

127 No se olvide que el patrimonio eclesiastico, a salvo de parcelaciones hereditarias y confiscaciones políticas y gozando, sobre eso, de exenciones fiscales, crece sin cesar desde los días de Constantino, y que, por otro lado, la persona del obispo, en su exclusiva posición de intermediario entre la 
razón por la que será pieza particularmente codiciada, tanto en la política de rentas de las grandes familias, como en el diseño de las estrategias clientelares de las mismas y de los gobernantes de turno. La Iglesia visigoda -Iglesia nacional, según se reconoce, desde el III concilio toledano del 589- no es ajena a estos procesos, y siente en propia carne la injerencia del poder terrenal en el nombramiento de obispos ${ }^{128}$. Sólo que, de esa forma, la figura y el ministerio episcopal corren el riesgo de que sean percibidos o interpretados desde el exterior a la luz de planteamientos puramente políticos, y tratados como un elemento más de las estrategias desarrolladas por los varios agentes sociales en su pugna por el poder. EI obispo de Pamplona, aun suponiendo que cuente con el apoyo de una nutrida comunidad creyente dentro de los muros de la ciudad y hasta en el inmediato hinterland aldeano, no puede sustraerse a ese condicionamiento básico, y pretender de las instancias de poder locales -cristianas o no, mas hostiles hipotéticamente a la dominación goda ${ }^{129}$ - que sea visto y acep-

comunidad de fieles y la de los santos, se aureola con el prestigio insondable de lo sacro y el que determina el nuevo evergetismo de inspiración cristiana.

128 Cfr. ThOMPSON, E. A. o. c., pp. 338s; J. ORLANDiS: La Iglesia en la España..., part. pp. 142149; Garcia Moreno, L. A. Historia de España..., pp. 352s. Para el caso aquitano, v. RouCHE, M. L'Aquitaine..., pp. 331-38.

129 No puede el fenómeno de la insurgencia vascona tardoantigua ser leído en clave de resistencia de ciertos grupos nobiliarios a determinados monancas, como parece ser el caso en episodios como los de la revuelta de Froya (tyrannidem sumens, dice de él el obispo Tajón) o la traición de Paulo (tratado también como tirano por Julián de Toledo), etc. En esos casos, los protagonistas de los movimientos sediciosos tienen nombres propios bien conocidos, y a los mismos se les supone aceptando de alguna forma el marco constitucional que viene a definir la propia monarquía goda electiva (supuesto explicitamente afimado en el caso de Paulo [v. JULIAN DE TOLEDO: Historia Wambae, 8]). Y no es ésa, por cierto, la impresión que se desprende de las fuentes, cuando en ellas se trata de los Vascones. Está, en primer lugar, que el enernigo, aquí, es designado con un etnónimo, como sucede por lo común cuando se trata de enemigos exteriores de la patria christiana (v. otros casos de utilización de etnónimos: Cantabri, Ruccones, Franci, miles Romanus o Romani..., protagonistas, todos ellos, de episodios de enfrentamiento con el poder godo, en que el enemigo es caracterizado indefectiblemente como exterior...). Está, luego, que, cuando son derrotados, se les exigen rehenes (v. ISIDORO: Hist. Goth., 63; JULIÁN DE TOLEDO: Historia Wambae, 10) -cual si de enemigos exteriores se tratasecomo salvaguardia de una sumisión o de una paz para la que, por las trazas, no resultan garantía suficiente los medios de disuasión de que dispone el propio aparato militar. Llegado el caso, pueden ciertamente los sediciosos del interior echar mano de los Vascones; pero antes habrán de ganárselos mediante pagos o promesas como a mercenarios que son: prolatis promissisque muneribus, Franco$\mathrm{rum}$ Vasconumque multitudines in auxilio sui pugnaturas allegit, dice JULIAN DE TOLEDO [Ibid.] referido a Paulo, poniendo en un mismo plano a los Franci (muy probablemente, el contingente aquitano-vascón que acompafia a Lupo en su marcha de apoyo a los sediciosos, pero que, en cualquier caso, nada tiene que ver con lo visigodo) y los Vascones. AJ respecto, nada resulta tan expresivo de la forma como perciben los coetáneos la lucha contra los Vascones, como el citado pasaje de ISIDORO (Hist. Goth., 63), referido a la campafia de Suintila de hacia el 621: derrotados por la exhibición de fuerza del rey visigodo los montivagi populi que habían incursionado en la Tarraconense, quasi debita iura noscentes [sejial de que antes se resistían a reconocerlos], deponen las armas, entregan rehenes y 
tado en su pura luz de ministro del altar y representante del Altísimo, sobre todo, si lo ven participando en unos sínodos generales que, a diferencia de los tradicionales - de ámbito provincial y esencial inspiración eclesiástica-, se definen como reuniones de marcado carácter político no menos que religioso, y de alcance a todas luces nacional.

Con tales condicionamientos de base, si la presencia del representante de la iglesia de Iruña en los concilios toledanos ha de ser vista como la señal inequívoca de que a la sazón el aparato de poder godo controla de forma eficiente la ciudad y sus vías de relación con el resto del Estado, sus ausencias -al menos, cuando son tan repetidas y duraderas - no parecen sino la prueba de una situación de inestabilidad en la zona e incluso, muy probablemente, el síntoma de que el control de la ciudad y/o de las vías de acceso a la misma se halla en otras manos. Hay un viejo texto referido a la historia de la ciudad ${ }^{130}-$ a remitir, según algunos ${ }^{131}$, a la etapa visigoda, aunque, para otros ${ }^{132}$, con mejores razones a nuestro modo de ver ${ }^{133}$, dataría de la carolingia--, que puede resultar expresivo de la situación que a la sazón toca vivir a la iglesia de Pamplona. En su laus el anónimo autor -clérigo o monje, sin ningún género de duda- se diría esforzarse en ahuyentar o exorcizar los temores y zozobras de una comunidad urbana que se siente hostigada "inter inimicas et barbaras gentes" (líneas más abajo, son identificados tales enemigos con los Bacei - a saber, Vaccei $=$ Vascones, según la reducción isidoriana de las Etymologiae ${ }^{134}$ ), evocando al objeto las defensas de que está dotada la ciudad, entre las que, junto a la protección del Señor, que dotó de singulares condiciones naturales a la plaza, y las reliquias de innumerables mártires, se cuentan las que ha habilitado la misma, que se cifran, con evidente exageración, en un recinto murado que se extiende por mil diestras de circuito, jalonado por 67 torres de 63 pies de espesor y 84 de altura. Como dicho, aunque el texto parece debe ser referido a la etapa carolingia de la ciudad, no por eso resultaría menos expresivo de la si-

\footnotetext{
fundan con sus stipendia (aportaciones tributarias) y trabajos (prestaciones personales en forma de operae et angaria, presumiblemente) Ia ciudad de los Godos Ologicus, prometiendo obediencia a su reino y a su autoridad (es decir, pasar a formar parte de la patria christiana gótica, señal inequívoca de que de momento, y a despecho de lo que pueda decir FREDEGARIO de Sisebuto [IV, 33], el suefio de unidad peninsular de Leovigildo -que persiste, ciertamente, como objetivo político- no se había hecho aín realidad del toxlo).

130 Se trata del De laude Pampilone (ed. de J. M. LACARRA: Textos navarros del Códice de Roda, en "Estudios de Edad Media de la Corona de Aragón" 1, 1945, 193-283, más precisamente pp. 269s). Sobre la forma en que ha llegado ese texto hasta nosotros, v. ibid., p. 268.

\$31 V., por ej., el mismo LACARRA, J. M. Textos navarros..., p. 268.

132 Cfr. DIAZ Y DIAZ, M. C. Libros y librerias en la Rioja altomedieval, Logrofo 1979, pp. 37s.

133 Cfr. LARRAÑAGA ELORZA, K. Glosa sobre un viejo texto referido a la historia de pamplona: el "De laude Pampilone", in "Príncipe de Viana" 55, 1994, 137-147.

$1349,2,107 \mathrm{~s}$.
}

Sobre la lglesia Medieval

Hispania Sacra 49 (1997) 
tuación que toca vivir a la comunidad cristiana visigoda que se cobija tras los muros de la ciudad tardoantigua. Aun suponiendo inclinaciones filogóticas en los titulares de la cátedra episcopal y/o en el equipo de presbíteros y diáconos de que se rodea - lo que puede entenderse perfectamente, caso de tratarse de "obispados de campaña puestos y repuestos por las armas godas" (hipótesis, ésta, que, según señalábamos arriba, no puede hoy por hoy decirse destituida de todo viso de fundamento...) - , sus visitas a Toledo no pueden resultar fáciles o cómodas, en tanto el aparato de poder godo no controle eficazmente el área y los caminos de acceso a la ciudad del Arga ${ }^{135}$. Pero es que, según lo dicho arriba, cabría todavía contemplar otra hipótesis: la de que, fuera de los momentos en que Toledo controla de veras la ciudad, los titulares de la sede episcopal respondan a otras fidelidades o intereses políticos, como en el caso citado de los obispos elusanos Palladius y Sennocus, condenados al exílio bajo la acusación de haberse aliado con los Vasçones ${ }^{136}$.

Visto todo lo cual, ¿puede extrañar que uno se sienta tentado a establecer una cierta relación ( ¿de causa a efecto?) entre presencias del obispo de Pamplona en los sínodos visigóticos y las acciones de fuerza del aparato de poder visigodo en el área norteña?

135 Sobre el régimen de comunicaciones a través de los puertos pirenaicos y, en concreto, del de Ibarieta en la ruta Asturica-Burdigala durante la Tarda Antigledad, v. M. Rouche: Les relations transpyrénéennes..., quien, empero, no se ocupa para nada, por no ser su objeto, de los accesos a la ciudad del Arga por otras rutas.

136 FREDEGARIUS: Chron., IV, 54 (ed. B. KRUSCH in en MGH, SRM, II, Hannover 1888, p. 148). 